REVIEW ARTICLE

\title{
Natural Compounds Targeting Cancer Stem Cells: A Promising Resource for Chemotherapy
}

\author{
Plabon K. Das ${ }^{1, \neq}$, Tasnim Zahan ${ }^{1, ¥}$, Md. Abdur Rakib ${ }^{1}$, Jahan A. Khanam ${ }^{1}$, Suja Pillai ${ }^{2}$ and Farhadul Islam ${ }^{1,2, *}$ \\ ${ }^{I}$ Department of Biochemistry and Molecular Biology, University of Rajshahi, Rajshahi-6205, Bangladesh; ${ }^{2}$ School of Biomedical \\ Sciences, Faculty of Medicine, The University of Queensland, Brisbane, Australia
}

\begin{abstract}
Background: Cancer Stem Cells (CSCs) are the subpopulation of cancer cells which are directly involved in drug resistance, metastases to distant organ and cancer recurrence.

Methods: A systemie literature search was conducted through various electronic databases including, Pubmed, Scopus, Google scholars using the keywords "cancer stem cells" and "natural compounds" in the present study. Articles published between 1999 and 2019 were reviewed. All the expositions concerning CSCs associated cancer pathogenesis and therapy resistance, as well as targeting these properties of CSCs by natural compounds were selected for the current study.

Results: Natural compounds have always been thought as a rich source of biologically active principles, which target aberrantly activated signaling pathways and other modalities of CSCs, while tethering painful side effects commonly involved in the first-line and second-line chemo-radiotherapies. In this review, we have described the key signaling pathways activated in CSCs to maintain their survival and highlighted how natural compounds interrupt these signaling pathways to minimize therapy resistance, pathogenesis and cancer recurrence properties of CSCs, thereby providing useful strategies to treat cancer or aid in cancer therapy improvement. Like normal stem cells, CSCs rely on different signaling pathways and other properties for their maintenance. Therefore, the success of cancer treatment depends on the development of proper anti-neoplastic drugs capable of intercepting those signaling pathways as well as other properties of CSCs in order to eradicate this evasive subpopulation of cancer cells.
\end{abstract}

A R T I CLE H I S T O R Y

Received: April 13, 2019 Revised: May 04, 2019 Accepted: May 20, 2019

DOI:

$10.2174 / 1871520619666190704111714$
Conclusion: Compounds of natural origin might act as an outstanding source to design novel therapies against cancer stem cells.

Keywords: Natural compounds, cancer stem cells, signaling pathways, cancer therapy, therapy resistance, pathogenesis.

\section{INTRODUCTION}

Cancer is a group of diseases that develop due to the accumulation of genetic and epigenetic alterations. These changes make one cell or few cells begin to grow and multiply indefinitely without control, resulting in an abnormal growth called tumor or neoplasm [1]. Despite the advancement in understanding the molecular basis, diagnosis and treatment of cancer, long-term survival rates of patients with cancer have to be achieved $[2,3]$. Resistance to the first line and second line chemo-radiotherapies and cancer recurrence contributed to the limited overall survival of patients with various types of cancer [4].

Emerging evidence suggested that a subpopulation of cancer cells known as Cancer Stem Cells (CSCs) are responsible for tumor initiation, therapy resistance, metastasis and recurrence [5-7]. In addition, these CSCs exhibit greater tumorigenic and metastatic potential than non-CSCs, i.e. bulk cancer cells [8]. Conventional first line and second line chemotherapy regimen (s) target bulk of tumor cells, thereby CSCs escaping these therapeutics due to their high resistance and can effectively repopulate a tumor [2]. Multiple

*Address correspondence to this author at the Department of Biochemistry and Molecular Biology, University of Rajshahi, Rajshahi-6205, Bangladesh; Tel: +880-721-711109; Fax: +880-721-750064; E-mail: farhad_bio83@ru.ac.bd ${ }^{\vee}$ Equal to first authors factors, including, escaping apoptotic insults, overactivation of drug-efflux pumps, increased DNA repair capacity, activation of detoxification enzyme and undergoing a quiescent state of CSCs attributed to the pro-survival mechanisms of CSCs, resulting in therapy resistance [9]. Moreover, several signaling pathways such as Wnt/ $\beta$-catenin, Hedgehog, and Notch signaling are highly active in many CSCs, thereby contributing to therapy resistance and cancer recurrence [10]. For example, activation of $\mathrm{Wnt} / \beta$-catenin promotes sphere formation, differentiation ability, self-renewal and tumor developmental cell fate in various cancer [10-12]. Activation of Notch signaling regulates morphogenesis and stem cell maintenance, whereas activation of Hedgehog signaling promotes expansion, proliferation, and self-renewal of stem cells [13]. Thus the development of therapeutics targeting these signaling pathways' component and/or mechanism attributed to drug resistance of CSCs, could have the potential to prevent drugs resistance and cancer recurrence $[14,15]$. Furthermore, side effects of conventional therapy limit their applications in clinical settings. For example, current chemotherapies such as using monoclonal antibodies, tyrosine kinase inhibitors and other targeted therapies have been associated with cardiovascular side-effects, including cardiomyopathy and congestive heart failure [16, 17]. Some of these agents are even involved with an increased risk of coronary artery disease with or without myocardial infarction [16]. However, nutraceuticals or compounds of natural origin, are beneficial to vascular health and impose less or no cardiovascular side effects [17]. Therefore, taking 
into account the less or no side effects and universal availability, researchers have shifted their focus on compounds of natural origin to identify novel therapeutics targeting CSCs [18]. Biologically active principles of natural origin have pharmacological applications against different types of diseases, including cancers [19]. Consequently, to deal with the difficulties of treating CSCs, natural compounds may be a potential resource to discover novel therapeutic options. Interestingly, the roles of natural compounds on a diminished activity of multiple signaling pathways and minor side effects have led researchers to investigate their effect on CSCs [19]. Natural compounds e.g. curcumin [20], quercetin and epigallocathechin gallate target the self-renewal pathways of CSCs, thereby providing a potential strategy to eradicate CSCs, resulting in nullifying tumor resistance and cancer relapse [21, 22]. Herein, in this review, we discuss the roles of the CSCs in tumorigenesis and therapy resistance along with the promising roles of natural compounds targeting CSCs. In addition, the mechanisms by which natural products exhibited their anti-CSCs activity have been presented.

\section{CANCER STEM CELLS (CSCS)}

Cancer Stem Cells (CSCs) are very similar to normal stem cells, especially with their ability to give rise to all cell types in a particular cancer [23]. In addition, CSCs share several properties with normal stem cells, including membrane transport, DNA repair, ability to regulate self-renewal and differentiation in response to oncogenic mutations and external stimulations [24]. However, they exhibit some distinct features e.g. spheroid formation in culture, expression of specific marker proteins (aldehyde dehydrogenase; ALDH, cluster of differentiation 133; CD133, cluster of differentiation 44; CD 44 etc), expression of multi-drug resistance proteins and anti-apoptotic proteins [25-28]. This subpopulation of cells may arise from normal stem cells or progenitor cells, adipose-derived stromal cells or even from differentiated cells through dedifferentiation [29]. CSCs are found in hematological cancers and in many solid tumors, including melanoma, osteosarcoma, prostate, ovarian, gastric, glioblastoma and their tumorigenic capability is highly influenced by tumor microenvironment [30, 31]. Furthermore, heterogeneity is another vital characteristic of CSCs that added more difficulties in designing therapy against these distinct phenotypes of tumour population [32]. Additionally, plasticity provides a dynamic ability, through which cells can switch from a non-CSC state to a CSC state and vice versa. Cancer cells gain this ability through specific microenvironmental signals and cellular interactions arising from the tumor niche [32].

\subsection{CSCs in Cancer Pathogenesis}

It is evident that CSCs play critical roles in all stages of tumorigenesis namely initiation, progression, invasion, metastasis, therapy resistance and recurrence [33, 34]. They guide metastasis through the Epithelial-Mesenchymal Transition (EMT) process [35]. Evidently, early metastatic cells that disseminated in the lungs exhibited stemness markers in mice model [36]. In addition, CSCs support angiogenesis via promoting the expression of angiogenic factors i.e. Epidermal Growth Factor (EGF), Platelet-Derived Growth Factor (PDGF), Vascular Endothelial Growth Factor (VEGF) etc, which stimulate new blood vessel formation [37]. Moreover, CSCs show vasculogenic mimicry activity [38]. Furthermore, aberrant activation of signaling pathways in CSCs has been involved in the manifestation of the pathophysiology of tumorigenesis [39].

\subsection{CSCs in Therapy Resistance}

The main challenge in current cancer treatment is therapy resistance, thereby cancer recurrence. This therapy resistance is contributed by CSC via multiple ways i.e. enhanced DNA repair efficiency, detoxification enzyme expression (ALDH), mutations in key signaling molecules, increased expression of drug resistance proteins, up-regulation of anti-apoptotic proteins (Bcl-2, Bcl-xL, Mcl-1, Bcl-w) and overexpression of drug efflux pumps [27, 40-42]. For instance, CD133+ glioma CSCs have been reported to the resistant of radiation therapy [41, 42]. Additionally, activation of oncogenes associated with the maintenance of stemness and tumorigenecity of CSCs [43, 44]. For example, RAD51, a recombinase, involved in DNA repair, is overexpressed in a treatment-resistant variety of tumors including ovarian, prostate, colorectal cancer and malignant gliomas [45, 46]. Moreover, CSCs showed up-regulation of several ATP-binding cassette (ABC) transporters family proteins (ABCG2, ABCB1, and CEACAM6) which efflux chemotherapeutic drugs efficiently [47]. Therefore, the molecular mechanism underlying CSCs therapy resistance opens up a new horizon for developing new drugs to treat cancer more effectively.

\section{NATURAL COMPOUNDS TARGETING CANCER STEM CELLS}

Traditional cancer therapies like chemotherapy and radiation therapy fail to target cancer stem cells and furthermore, nonspecificity of these therapies causes toxicity to normal cells [15]. Interestingly, many natural compounds have already demonstrated anti-CSCs properties both in vivo and in vitro [19]. These finding suggested that natural compounds may have the potential to induce death of CSC. Besides that, natural compounds could make them sensitize to conventional therapies, forcing them to re-differentiate or preventing them from entering a dormant or resistant state, thereby having the potential of improving cancer management in clinical settings [19]. In the following sections, the roles of natural compounds against CSCs in various cancers are described.

\subsection{Natural Compounds Targeting Signaling Pathways in CSCs}

There are several signaling pathways such as $W n t / \beta$-catenin, Notch, Hedgehog signaling overactivated in CSCs. Diverse alteration in these signaling pathways accumulated in CSCs and contributed to cancer initiation, progression, and recurrence [15]. Natural compounds exhibit anti-CSCs activity by interrupting different signaling pathways or their components are summarized in Table $\mathbf{1}$.

\subsection{Natural Compounds Targeting the Wnt/ק-Catenin Signal- ing Pathway}

Wnt/ $\beta$-catenin signaling is strongly associated with tumor formation in different types of cancer [11]. This pathway is a key player in the initiation and progression as the elevated levels of $\beta$ catenin could direct the cell fate [48, 49]. Tumorigenic properties of CSCs such as sphere formation, differentiation, and in vivo tumor development abilities of CSCs are regulated by Wnt/ $\beta$-catenin signaling [50]. Natural compounds such as Epigallocatechin-3Gallate (EGCG), Diallyl trisulphide (DATS), Chinese Bayberry Leaf Proanthocyanidins (BLP), Ginsenoside Rb1, Sulforaphane and Isoliquiritigenin have the potential to interact with the elements of $\mathrm{Wnt} / \beta$-catenin signaling, resulting in inhibition of CSCs growth and development (Fig. 1) [50-56]. For example, Epigallocatechin-3Gallate (EGCG) has been isolated from green tea (Camellia sinensis), interacts with Wnt/ $\beta$-catenin signaling component GSK3 $\beta$ in DLD-1 and SW480 colon cancer cell lines, thereby inhibiting their growth and proliferation. Treatment of colon cancer cells with EGCG downregulates the expression of p-GSK3 $\beta$ (inactivated) and up-regulates the expression of GSK3 $\beta$ (activated), consequently decreasing the level of $\beta$-catenin and its target gene c-myc, resulting in reduced cell growth and proliferation (Fig. 1) [50]. Though, in vivo anti-CSCs activity of EGCG in colon cancer has not been evaluated yet, accumulating evidence has shown that EGCG exhibits anti-cancer properties in various types of cancers, including bladder cancer [57], melanoma [58] and lung cancer [59]. It exhib- 
Table 1. Different natural compounds target different pathways in various cancer types.

\begin{tabular}{|c|c|c|c|c|}
\hline Natural Compounds & Source & Target Pathway (s) & CSCs in Cancer Types & Refs. \\
\hline EGCG & Camellia sinensis & Wnt/ $\beta$-catenin & Colon & {$[50]$} \\
\hline DATS & Allium sativum & Wnt/ $\beta$-catenin & Colon & [51] \\
\hline BLP & Morella rubra & Wnt/ $\beta$-catenin & Ovarian & {$[52]$} \\
\hline Compound $\mathrm{k}$ & Panux quinquefoliu & Wnt/ $\beta$-catenin & Ovarian & {$[53]$} \\
\hline Isoliquiritegenin & Glycyrrhizaglabra & Wnt $/ \beta$-catenin & Breast & {$[55,56]$} \\
\hline Sulforaphane & Brassica oleracea var. & Wnt/ $\beta$-catenin, Notch, Hedgehog & Breast, Pancreatic & {$[55,56]$} \\
\hline Alpinetin & Alpinia zerumbet & Notch & Glioblastoma & {$[66]$} \\
\hline Eckol & Ecklonia cava & Notch, PI3K-Akt and Ras-Raf-1-Erk. & Glioblastoma & {$[67]$} \\
\hline Genistein & Glycine max & Hedgehog & Breast & [75] \\
\hline Honokiol & Magnolia officianalis & Notch & Melanoma & [69] \\
\hline Cyclopamine & Veratrum californicum & Hedgehog & Leukemia & [72] \\
\hline Nitidine chloride & Zanthoxylum nitidum & Hedgehog & Breast & [73] \\
\hline Hinokitiol & Chamacyparis taiwanensis & Nrf2 & Glioblastoma & [76] \\
\hline Plumbagin & Plumbago zeylanica & Nrf2 & Scquamous carcinoma & {$[84]$} \\
\hline Triptolide & Tripterygium wilfordii & Nrf2 & Leukemia & {$[85]$} \\
\hline BBMD3, synthetic derivative of Berbamine & Berberis amurensis & JNK/AP-1 & Glioblastoma, Osteosarcoma & [86-87] \\
\hline Compound 2 & Garcinia hanburyi, Garcinia Morella & Akt/Erk & Head and neck & {$[88]$} \\
\hline BMR270 (extract) & Medicinal Plants & NF-k $\beta$ & Osteosarcoma & [78] \\
\hline Nutraceuticals & Medicinal Plants & - & - & 17 \\
\hline
\end{tabular}

Note-EGCG: Epigallocatechin-3-Gallate; DATS: Diallyl trisulphide; BLP: Bayberry leaf proanthocyanidins; PI3K: Phosphatidylinositol 3-kinase; Akt: Protein kinase B; Raf: Rapidly Accelerated Fibrosarcoma; Nrf2: NF-E2-related factor 2; JNK:c-Jun $\mathrm{NH}_{2}$-terminal kinase (JNK); AP-1: Activator protein-1; Erk: Extracellular-regulated kinase; NF-k $\beta$ : Nuclear factor kappa $\beta$.

ited its anti-cancer activity by inhibition of proliferation [60] and induction of apoptosis of cancer cells [61]. It was suggested that the inhibitory effects of EGCG may vary depending on the type of CSCs, therefore, further investigations are needed to make a link of the activity of EGCG in different cancers. Similarly, Diallyl Trisulphide (DATS) extracted from garlic (Allium sativum) exhibits similar activities against colon cancer cells [51]. The effect of DATS on GSK3 $\beta$ in colon CSCs has been confirmed using the treatment of $\mathrm{LiCl}$, a known GSK3 $\beta$ inhibitor [51].

Sulforaphane, a dietary compound isolated from broccoli (Brassica oleracea var.) downregulates $\mathrm{Wnt} / \beta$-catenin pathway in human breast cancer cells [54]. This compound decreased the expression of $\beta$-catenin up to $85 \%$ as well as decreased the expression of cyclin D1 by $77 \%$ in MCF-7 and SUM159 cell lines. Furthermore, in vivo activity of sulforaphane was also determined in breast cancer cells injected immunocompromised NOD/SCID mice. Daily injection of sulphoraphane for two weeks decreased tumor growth in primary NOD/SCID mice and reduced ALDH-positive cell population of the tumors by $\sim 50 \%$. More importantly, they found that the tumor cells derived from sulforaphane-treated mice were not able to form secondary tumors in recipient mice up to 33 days of implantation [54]. However, sulforaphane could act as a double-edged sword. On the one hand, it reduces carcinogenesis ; on the other hand, it blocks the $\mathrm{T}$ cell-mediated immune response which is important for immune surveillance of tumors [62]. Sulforaphane inhibits T cell activation and $\mathrm{T}$ cell effector functions by increasing intracellular ROS levels and decreasing GSH [62]. Thus, it could interfere with the successful application of immunotherapy by immune checkpoint inhibitors (e.g. CTLA-4 antibodies and PD-1/PD-L1 antibodies) or chimeric antigen receptor (CAR) $\mathrm{T}$ cells [62]. All these setbacks should be considered before applying sulforaphane in human.

Another natural compound BLP, isolated from Chinese bayberry (Morella Rubra) leaf, targets Wnt / $\beta$-catenin signaling and induces degradation of $\beta$-catenin in ovarian cancer cells [52]. BLP stimulates degradation of $\beta$-catenin in a dose-dependent manner by up-regulation of p-GSK3 $\beta$ and reduction of non-phosphorylated GSK3 $\beta$ along with inhibition of Akt activity [52]. Subsequently, the expression of $\beta$-catenin downstream targets genes such as cyclin D1 and c-myc was down-regulated, resulting in reduced cell growth and proliferation.

Ginsenoside $\mathrm{Rb} 1$, is a natural saponin, isolated from the rhizome of Panux quinquefoliu and its metabolite compound $\mathrm{k}$ has the potential to target Wnt/ $\beta$-catenin signaling, thereby inhibiting CSCs growth and reversing therapy resistance of ovarian cancer cells both in vivo and in vitro [53]. Compound $\mathrm{k}$ induced inhibition of ABCG2 and p-glycoprotein expression (two critical drug transporters) by interrupting the binding of $\beta$-catenin with T-cell factor (TCF/LEF) (Fig. 1). The binding of $\beta$-catenin to TCF/LEF is critical for mediating its downstream function such as transcription of target genes involved in cell growth, division and survival [53]. Thus, treatment of CSCs with compound $\mathrm{k}$ inhibits Wnt/ $\beta$-catenin signaling, resulting in reduced cell growth and proliferation.

Isoliquiritigenin (ISL) isolated from Licorice root exhibited anti-CSCs activity in both MMTV-PyMT mice model and breast cancer cells (MDA-MB-231), by targeting the Wnt/ $\beta$-catenin signaling pathway via modulating WIF1 expression [55]. Treatment of CSCs with ISL induces down-regulation of both the cytoplsolic and nuclear $\beta$-catenin expression, indicating that downregulation of $\beta$ catenin might occur in post-translational level. Furthermore, a WIF1-antibody was used to examine whether this effect is critical for down-regulation of $\beta$-catenin or not. It was noted that inhibition of WIF1 reverses the downregulation of $\beta$-catenin expression in MDA-MB-231 breast cancer cells followed by ISL treatment. Evidently, the expression of $\beta$-catenin was increased significantly with the supplementary WIF1-neutralizing antibody. These results indicate that ISL interacts with the Wnt/ $\beta$-catenin pathway through modulating WIF1 expression [55]. Moreover, inhibition of $\beta$ catenin expression resulted in increasing chemosensitivity of cancer 


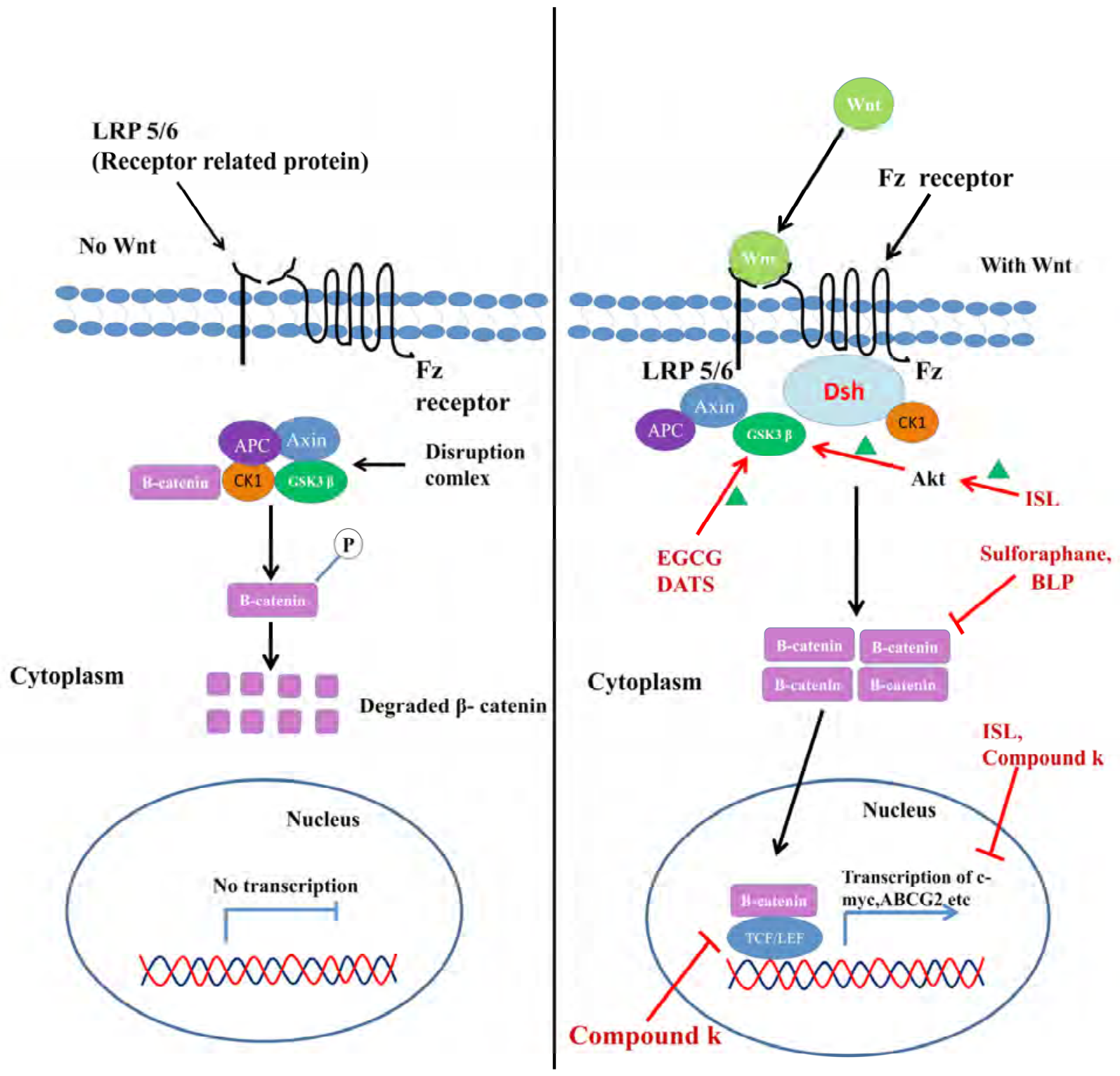

Fig. (1). The Wnt/ $\beta$-catenin signaling and its interference by natural compounds. Binding of Wnt to the cell surface Frizzled receptors, facilitates translocation and deactivation of $\beta$-catenin disruption complex (APC/Axin/CK1/GSK3 $\beta$ complex). As a result, $\beta$-catenin accumulates and translocates into the nucleus to activate transcription of target genes by interacting with transcription activator. However in the absence of Wnt expression, disruption complex degrades $\beta$-catenin. Consequently, inactivation of downstream signaling occurs. Natural compounds like EGCG, ISL and DATS upregulate the expression of disruption complex component GSK3 $\beta$, resulting in an increase of $\beta$-catenin degradation. Whereas sulforaphane, BLP inhibit the expression of $\beta$-catenin and compound $\mathrm{k}$ inhibits the expression of $\beta$-catenin downstream genes. Compound $\mathrm{k}$ also inhibits the binding of $\beta$-catenin to transcription activator.APC: Adenomatous polyposis coli;GSK: Glycogen synthase kinase;CK1 $\alpha$ : Casein kinase $1 \alpha$;Dsh: Dishevelled; LRP-5/6: Lipoprotein receptor-related protein5/6;TCF/LEF: T-cell factor/ymphoid enhancer-binding factor proteins; EGCG: Epigallocatechin-3-Gallate; DATS: Diallyl trisulphide;BLP: Bayberry leaf proanthocyanidins; ISL: Isoliquiritigenin.

cells with the treatment of ISL by down-regulation of ABCG2, which is a downstream target gene of $\beta$-catenin (Fig. 1). In addition, ISL exhibited synergistic anti-CSC activity when applied with epirubicin (an anticancer drug) via inducing reduced expression of $\beta$ catenin and ABCG2 [55]. Inhibition of $\beta$-catenin downstream genes including cyclin D1, survivin, Oct-4, c-myc, and ABCG2 in ISL treated cells suggested that $\beta$-catenin inhibition might occur at the post-translational level. Furthermore, it was demonstrated that ISL induces proteasomal degradation of $\beta$-catenin by interacting Akt/GSK3 $\beta$ pathway [55]. Moreover, using drug affinity responsive target stability strategy, it was further identified that ISL directly targets GRP78. Subsequent molecular docking analysis and functional studies demonstrated that ISL could dock into the ATP do- main of GRP78 and thereby inhibit its ATPase activity, resulting in dissociation of GRP78 from $\beta$-catenin. Also, an in vivo study suggested that ISL could chemosensitize breast CSCs via the GRP78/ $/$-catenin/ABCG2 pathway, with little toxicity in normal tissues and mammary stem cells [56]. Therefore, anti-CSCs activities of different natural compound provide a new horizon by interrupting aberrant activation of $\mathrm{Wnt} / \beta$-catenin signaling.

\subsection{Natural Compounds Targeting the Notch Signaling Pathway}

Notch signaling, an evolutionarily conserved pathway, plays a pivotal role in embryonic development, organ development and the regulation of self-renewal in normal stem cells and subsequently maintains tissue homeostasis $[63,64]$. However, in the context of 


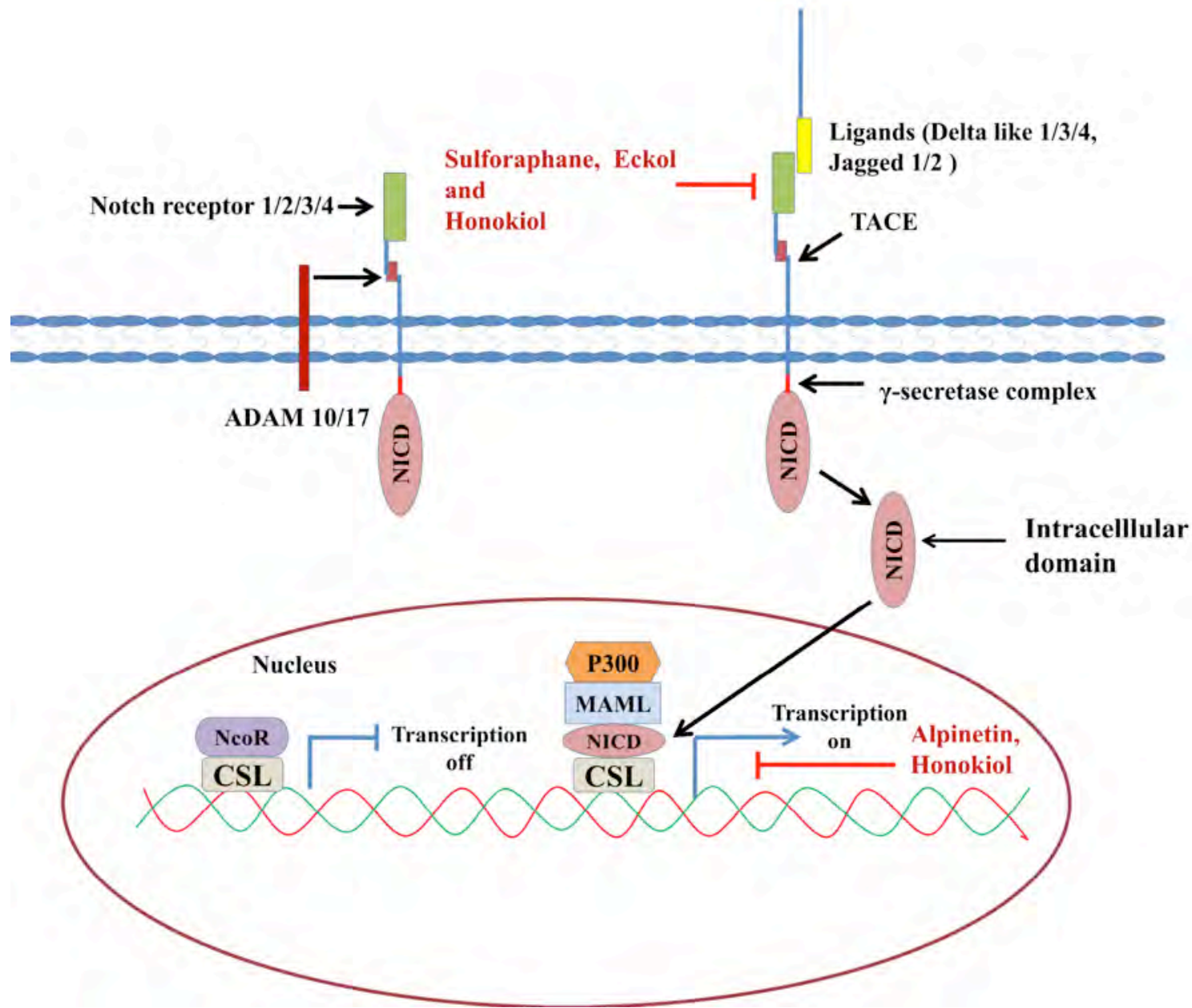

Fig. (2). The Notch signaling and its interferencenatural compounds. Ligand binding to the Notch receptor leads to unmask the ADAM cleavage site. Consequently, the Notch receptor is cleaved by ADAM metalloprotease TACE (Tumor Necrosis Factor- $\alpha$-Converting Enzyme) and produces Notch extracellular truncation fragment which is a substrate for $\gamma$-secretase complex. Further $\gamma$-secretase complex mediated cleavage releases intracellular domain NICD which then translocates to the nucleus and associates with CSL, a DNA binding protein. Consequently transcription of target genes is switched on. Compounds like sulforaphane, eckol and honokiol inhibit the expression of Notch receptors. On the other hand, alpenitin and honokiol reduce the expression of Notch target genes. ADAM: A Disintegrin and Metalloprotease; TACE: Tumor Necrosis Factor- $\alpha$-Converting Enzyme; NICD: Notch intracellular domain; CSL: CBF-1-Suppressor of Hairless/Lag1; NcoR: Nuclear co-repressors MAML: Mastermind-like protein.

disrupting signaling pathways, this signaling is intensively activated in CSCs and mediates the critical processes of carcinogenesis, including angiogenesis, EMT and metastatic spread of a tumor [65]. A number of natural compounds such as Alpinetin, Eckol, Sulforaphane, and Honokiol isolated from medicinal and edible plants, exhibited anti-tumor activities by targeting CSCs in many cancer via suppressing Notch singling pathway (Fig. 2) [66-69]. For instance, alpinetin isolated from edible plants such as Alpinia zerumbet, can reduce the invasiveness, proliferation and induce apoptosis in a dose and time-dependent manner in orthopic GSC xenograft model [66]. In GSC, alpinetin induced proteolytic cleavage of Notch protein thereby reducing the expression of Notch target genes i.e. HES and $c-M y c$ [66]. Eckol, another natural compound isolated from brown algae Ecklonia cava showed anti-CSCs activity via reducing the expression of Notch protein in GSC [67].

Additionally, sulforaphane induced down-regulation of Notch-1 expression in pancreatic CSC [68]. Consistently, downregulation of Notch-1 caused inhibition of c-Rel (a transactivation-potent subunit of the NF- $\mathrm{BB}$ transcription factor) expression, resulting in inactivation of NF- $\kappa B$ signaling in pancreatic CSC [68]. Thus, sulforaphane could potentially inhibit NF- $\kappa \mathrm{B}$ signaling in CSC through Notch-1 downregulation (Fig. 2). Furthermore, a recent study reported that honokiol, a biphenolic compound extracted from Magnolia Officinalis, suppresses the aberrant activation of Notch signaling in mesenchymal stem cells of B16/F-10 and SKMEL-28 melanoma cell lines [69]. Proteolytic cleavage of the Notch receptor is crucial to inactivate Notch signaling and interestingly it was noted that honokiol treatment induced proteolytic degradation of Notch-2 receptor in melanoma CSCs [69]. Subsequently, the expression of downstream targets of Notch signaling such as Hes-1 and cyclin D1 was declined in honokiol treated mesenchymal stem cells, thereby inhibiting growth and proliferation of melanoma stem cells (Fig. 2) [69]. As the Notch signaling pathway is deeply associated with cancer progression, therefore targeting this pathway by these natural compounds may provide a fruitful way to treat cancer.

\subsection{Natural Compounds Targeting the Hedgehog Signaling Pathway}

The Hedgehog pathway mediates the embryonic development of both vertebrates and invertebrates and also contributes to organ and tissue formation including neural tube [70]. As a consequence, like Wnt/ $\beta$-catenin and Notch signaling, aberrant activation of Hedgehog pathway has also been noted in CSCs, which plays a vital role in multiple steps of tumor progression, including migra- 


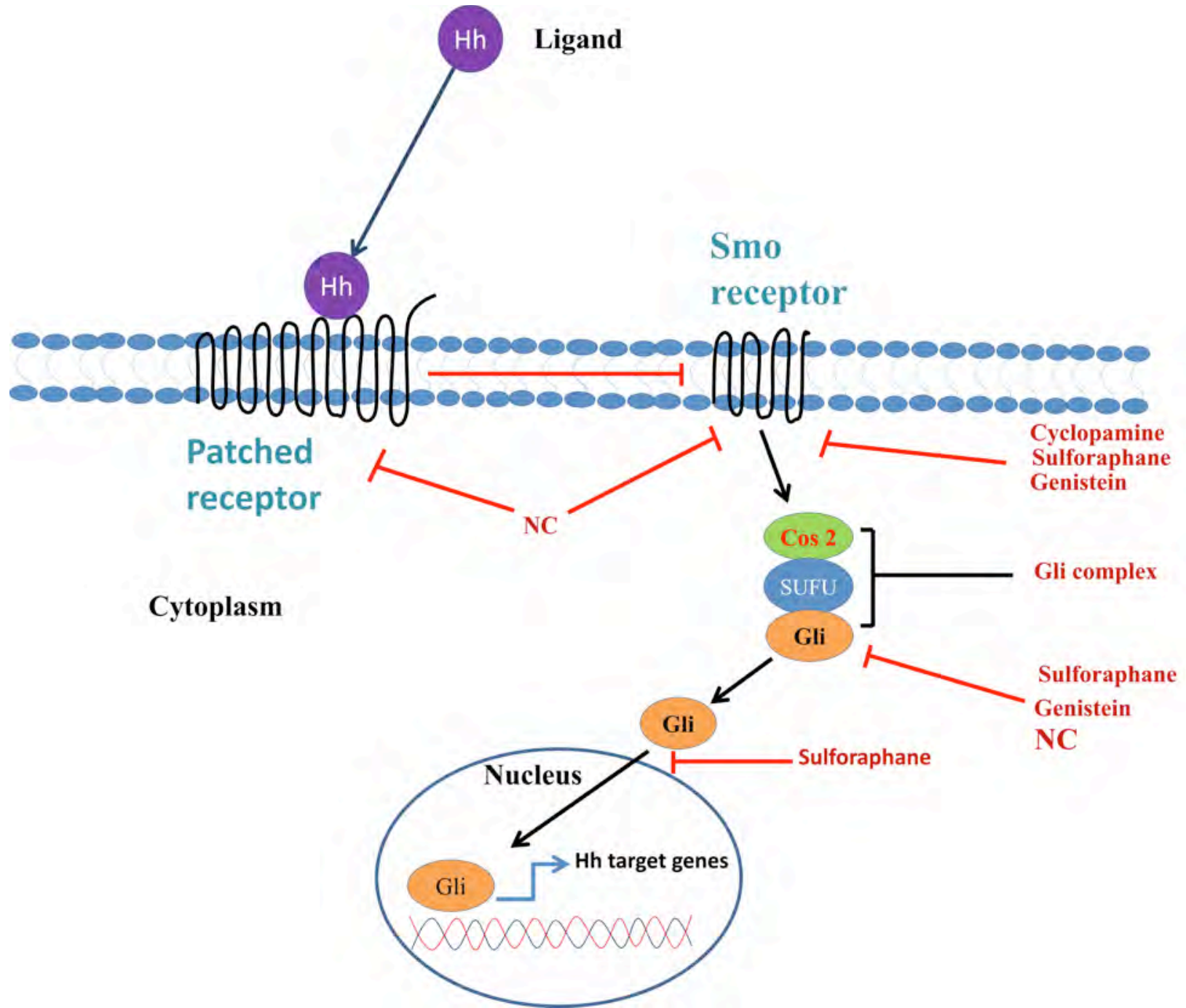

Fig. (3). Hedgehog signaling and its interference in natural compounds. Upon binding of Hedgehog ligand (Hh) to Patched receptor, Smo is activated (Pathched generally inactivates Smo when it is not engaged with ligand). Then Smo brings about the translocation of Gli protein into the nucleus, subsequently causes the transcription of downstream genes. Compounds such as cyclopamine and genistein decrease the expression of Smo. Whereas nitidine chloride downregulates the expression of both Smo and Patched receptors. On the other hand sulforaphane, nitidine chloride and genistein decrease the expression of Gli protein. Sulforaphane also reduces the expression of Smo, Gli and inhibits the nuclear translocation of Gli. Smo: Smoothened; Cos 2: Costal-2; SUFU: Suppressor of fused homolog; Hh: Hedgehog ligand.

tion, invasion, and metastasis [71]. Treatment of cancer cells with compounds of natural origin such as Cyclopamine, Nitidine chloride, Sulforaphane, Genistein could potentially kill CSCs by targeting the Hedgehog pathway components, resulting in inactivation of signaling cascade (Fig. 3) [72-75]. For example, cyclopamine is a teratogen isolated from the Veratrum californicum, induced apoptosis in CD34+ AML cancer stem cells [72]. Cyclopamine affects the survival of AML stem cells by modulating $G$ protein-coupled receptor Smo. Moreover, the anti-CSCs effect of cyclopamine was noted to be stem cell-specific as it fails to exhibit growth inhibitions or survival of leukemia cells lacking expression of Hedgehog receptor components [72]. In addition, treatment of drug-resistant CD34+ (resistant to cytarabine) with cyclopamine increased the chemosensitivity of CD34+ cell lines against cytarabine (Fig. 3) [72]. Nitidine Chloride (NC) derived from roots of Zanthoxylum nitidum targets Hh signaling MDA-MB-468 and MCF-7 breast cancer cell lines via inducing downregulation of $\mathrm{Hh}$ receptors (Smo, Patched) and activators Gli1, Gli2 [73]. NC in combination with Smo inhibitor cyclopamine exhibited synergistic effect ofGli and CD44 marker downregulation as well as inhibited the migration of breast cancer cells [73].
In addition to the inhibition of Wnt/ $\beta$-catenin and Notch signaling, Sulforaphane significantly inactivates $\mathrm{Hh}$ signaling in pancreatic cancer stem cell [74]. In pancreatic CSCs, hyperactive Sonic Hh signaling is involved in the regulation of stemness genes expression [74]. It was demonstrated that Sulforaphane treatment can target Hedgehog signaling in pancreatic CSCs and reduced the expression of Smo (receptor), Gli1 and Gli2 (effectors). Moreover, sulforaphane treatment can inhibit nuclear translocation of both Gli1 and Gli2 transcriptional effectors in a dose-dependent fashion. Consistently, the downstream targets of Hh signaling especially in pancreatic CSCs, which are involved in proliferation undergo downregulation, thereby inhibit cell growth and proliferation [74] (Fig. 3).

Another natural isoflavone Genistein of Glycine max inhibits breast cancer stem cells originated from MCF-7 cells via targetingHedgehog-Gli1 signaling pathway [75]. Genistein induces reduced expression of Smo and Gli1 at both mRNA and protein level in breast cancer CSCs [75]. Therefore, natural compounds exert their anti-CSCs effect by targeting key singling pathway components or inducing down-regulation of their targets, resulting in inhibition of cancer cell growth and proliferation. The findings of the of these 
studies led us to the hypothesis that these compounds could provide a way to make suitable anticancer drug by targeting key singling pathways or their components in CSCs.

\subsection{Natural Compounds Targeting Other Pathways in CSCs}

There are some other signaling pathways such as NF-E2-related factor 2 (Nrf2), JNK/AP-1, NF- $\kappa \mathrm{B}$ etc which are also implicated in CSCs $[76,78]$. Thus, targeting these pathways by naturally occurring compounds is of great importance as well. Nrf2 is thought of as a useful factor that protects human from carcinogenic chemicals [79]. It is a transcription factor that helps chemotherapeutic compound including detoxifying enzyme, antioxidants, and transporters to defend the cells from carcinogenic insults [79]. Moreover, it is evident that Nrf2 plays dual roles in cancer pathogenesis i.e. protects normal cells from transforming into cancer cells, and also nourishes the survival of cancer cells in tumor microenvironment [79]. A growing body of evidence suggests that increased activity of Nrf2 due to NFE2L2 or KEAP1 (Kelch-like ECH associated protein 1) mutations play a significant role in the pathogenesis of many solid tumors [80]. For instance, it has recently emerged as one of the main pathways implicated in renal carcinoma [80]. Moreover, it was also demonstrated that KEAP1-Nrf2 polymorphism also occurred in breast cancer [81]. In addition, Nrf2 promotes metastatic breast cancer cell migration via-upregulation of glucose-6-phosphate dehydrogenase (G6PD), Hypoxia-inducing factor $1 \alpha(\mathrm{HIF}-1 \alpha)$ in MCF-7 and MDA-MB-231 cells [82]. Furthermore, in lung cancer, it was observed that, Keap1-Nrf2 signaling plays a critical role in response to oxidative stress. Mutations in KEAP1/NFE2L2 genes always cause persistent Nrf2 activation in lung cancer cells that confer therapeutic resistance and aggressive tumorigenic activity [83]. Thus, Nrf2 suppression with chemical agents which cause enhanced oxidative imbalance or abnormal metabolism would be promising in the treatment of lung adenocarcinoma. Targeting Nrf2 with natural compounds could induce down-regulation of Nrf2, subsequently inhibiting its tumor promoting activity. It was reported that $\mathrm{Nrf} 2$ expression was upregulated in Glioma stem cells [76]. Treatment of these cells with a natural bioactive compound Hinokitiol, isolated from Chamacyparis taiwanensis induces down-regulation of $\mathrm{Nrf} 2$ in Glioma stem cells in a dose-dependent manner. In addition, it inhibited the expression of Nrf2 target genes such as heme oxygenase 1 (HO-1) and glutathione S-transferase, thereby nullifying Nrf2 mediated carcinogenic insults in Glioma stem cells [76]. Plumbagin, a natural naphthoquinone isolated from Plumbago zeylanica, inhibited nuclear translocation of Nrf2, resulting in inactivation of Nrf2-mediated oxidative stress signaling pathway in squamous cell carcinoma cells [84]. It was noted that treatment of squamous cell carcinoma cells with Plumbagin induces reduced proliferation, activated death receptormediated apoptosis and inhibited epithelial to mesenchymal transition, thereby reducing CSCs' properties of squamous cell carcinoma cells [84]. Furthermore, Triptolide, (a bioactive diterpenoid triepoxide of Chinese medicinal plant Tripterygium wilfordii) has been found to be effective against Leukemia stem-like cells via downregulation of Nrf2 pathway [85].

The stress-responsive JNK/AP-1 signaling pathway is involved in cell growth, transformation and apoptosis [77]. JNK-1 and JNK2 are key mediators of this pathway, which cause phosphorylation of c-Jun, a major protein of activator protein-1 complex. Activation of JNK/AP-1 signaling pathway usually induces apoptosis [77]. A bioactive natural compound can activate this pathway via interaction with the components and could induce anti-CSC activity in cancer. For example, Berbamine isolated from Berberis amurensis and its synthetic derivative BBMD3 exhibited anti-cancer effects in glioblastoma-derived cancer stem-like cells through activation of JNK/AP-1 signaling pathway [86]. In addition, BBMD3 inhibited cell viability and induced apoptosis in human osteosarcoma cells via activation of JNK/AP-1 [87].
EGFR, an intrinsic tyrosine kinase, when binds with its ligand EGF, results in autophosphorylation of tyrosine residues on the EGFR and subsequently activating signal transduction pathways that involved in regulating cellular proliferation, differentiation, and survival [88]. Up-regulation of EGFR occurred in head and neck squamous cell carcinoma [88]. Compound 2, a derivative of Chinese medicine called gambose (prepared from Garcinia hanburyi, Garcinia Morella like plants), exerted dose-dependent inhibitory effect against head and neck squamous cancer stem-like cells in xenograft tumor model via downregulation of EGFR and phosphorylation of Akt and Erk [88].

The transcription factor NF- $\kappa \mathrm{B}$ stimulates expression of antiapoptotic genes. Hence, overexpression of NF- $\kappa \mathrm{B}$ induces tumorigenesis in association with Cdk6 and p65 in the stem-like cancerinitiating cells in osteosarcoma-derived cells [78]. Plant extract BMR270 treatment dramatically inactivates NF- $\mathrm{B}$ signaling cascade in MDR-induced stem-like cancer-initiating cells in osteosarcoma derived CSCs [78]. Thus, besides Wnt/ $\beta$-catenin, Notch, Hedgehog signaling, other pathways like Nrf2, EGFR and NF- $\kappa B$ are also involved in CSCs properties. Therefore, inhibition of these pathways or their components by natural compound may provide a way to treat cancer.

\subsection{Natural Compounds Targeting Other Modalities of CSCs Rather Than Signaling Pathways}

There are a number of natural compounds that do not directly target signaling pathways or their molecular mechanisms are yet to be discovered (Table 2). In the following sections, we will review those compounds of natural origin that could potentially target CSCs.

MicroRNAs (miRNAs), a class of small noncoding RNAs, regulate the expression of a gene at the post-transcriptional level by binding to target mRNAs within the $3^{\prime}$ untranslated region (UTR) [89]. They have been found to be involved in many important biological processes [89-91]. For example, miR-218 acts as a tumor suppressor by targeting many oncogenes related to proliferation, apoptosis, and invasion [92-94]. A number of studies have shown that miRNA engaged in the regulation of CSCs properties [93-95]. Andrographolide, a bioactive compound isolated from Andrographis paniculata, inhibited cell proliferation and self-renewal of oral cancer stem cells by increasing the expression of miRNA-218 [95]. MiR-218 induces downregulation of Bmil, which is a transcription factor associated with self-renewal, tumor cell motility and invasion of Oral Cancer Stem Cells (OCSC) [95]. In addition, Andrographolide supplementation mediated downregulation of Bmil through up-regulation of miRNA-218, which subsequently inhibits tumor growth in immunocompromised mice bearing OCSC xenograft [95].

Hinokitiol, also known as $\beta$-thujaplicin, isolated from heartwood cupressaceous (Cupressus sempervirens, Hinoki cypress), inhibits vasculogenic mimicry activity in breast cancer stem cells by stimulating proteasomal degradation of EGFR [96]. In addition, Hinokitiol inhibited colony formation ability of glioma stem cells and reduced cell viability in a dose-dependent manner [97].

Dietary compound isoliquiritigenin (ISL) reduces colony forming and invasive activities of Oral Squamous Cell Carcinoma Cancer Stem Cells (OSCC-CSC) when administered alone or in combination with cisplatin [98]. ISL treatment in OSCC-CSC induced down-regulation of CD44, ABCG2 and cell surface GRP78 protein expression in OSCC-CSCs [92]. GRP78 is a component of GRP78/BiP/HSPA5 chaperon which anchors in the cell membrane and promotes tumor cell proliferation [99]. Thus, ISL exerts chemosensitizing effects via GRP78 in OSCC-CSCs as GRP78 is the direct target of ISL in inhibiting $\beta$-catenin/ABCG2 signaling [98]. 
Table 2. Natural compounds those mediate their function by targeting other features of CSCs rather than signaling pathways.

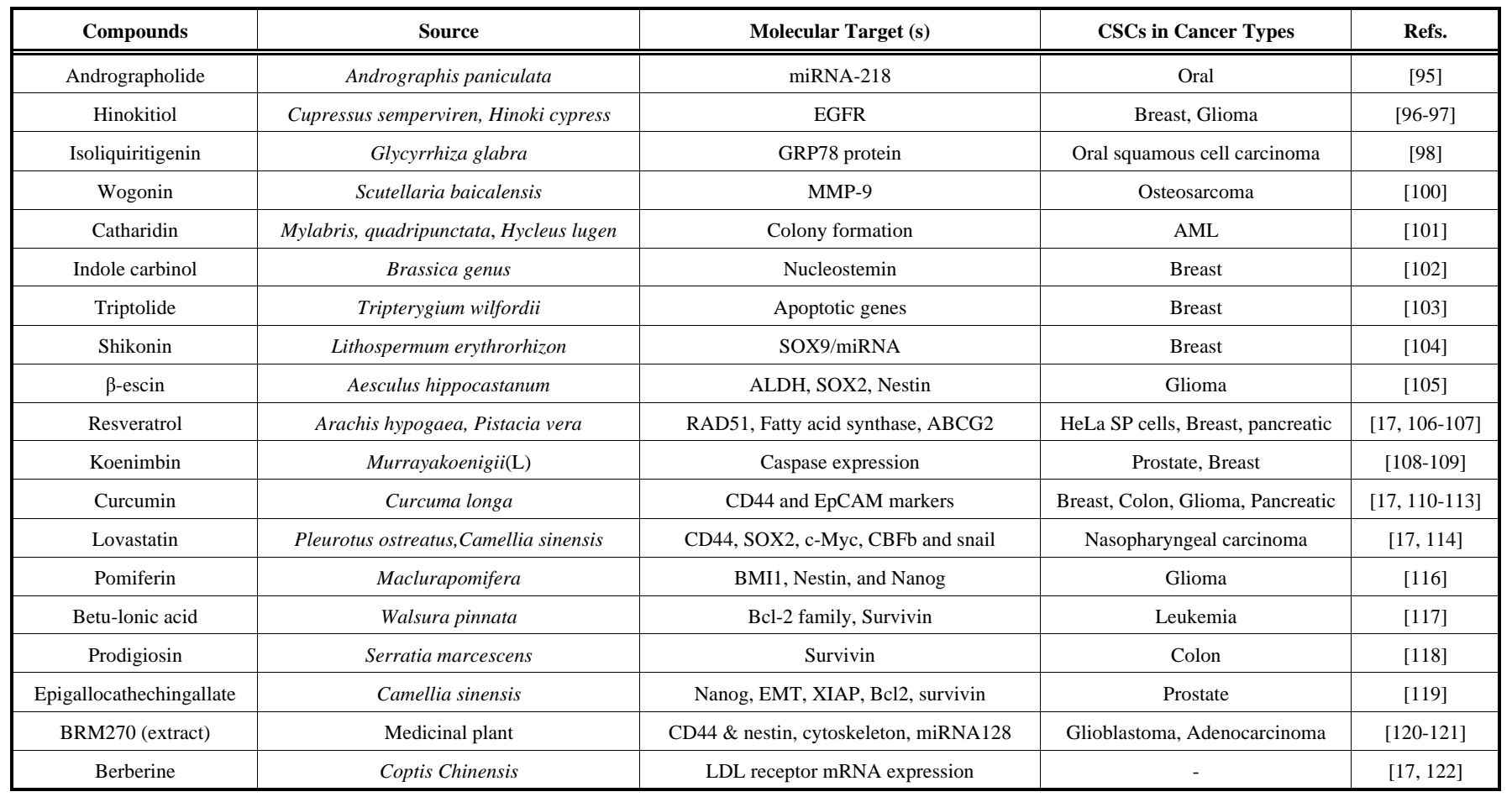

Note-EGFR: Epidermal growth factor receptor; GRP78: Glucose-regulated protein 78; MMP-9:Matrix metallopeptidase 9; SOX 9:Sry-box transcription factors 9;ALDH: Aldehyde dehydrogenase; ABCG2: ATP binding cassette subfamily G member 2; CD44: Cluster of differentiation 44; EpCAM: Epithelial cell adhesion molecule; c-Myc:Avian myelocytomatosis virus oncogene cellular homolog; CBFb: core binding factor $\beta$; BMI1: B cell-specific Moloney murine leukemia virus integration site 1; Bcl-2: B cell leukemia 2 protein;EMT: Epithelial mesenchymal transition;XIAP:X-linked inhibitor of apoptosis protein.

Matrix Metalloproteinase (MMP-9) facilitates the tumor invasion and metastasis [100]. Wogonin is isolated from the root of Scutellaria baicalensis, and inhibits the mobilization of Osteosarcoma CSC by downregulation of Matrix Metalloproteinase (MMP9) [100]. In vitro assays such as Gelatin zymography and western blotting assay were used to determine MMP-9 activity in osteosarcoma CSCs [100]. It was noted that MMP-9 activity is decreased significantly by wogonin supplementation at the concentrations of $40-80 \mu \mathrm{M}$ in comparison to that of control [100]. In addition, wogonin treatment induce reduced growth of sphere and inhibits the colony formation significantly in CD133+ CAL72 CSCs [100].

Catharidin, one type of terpenoids produced by blister beetles readily, targets leukemia stem cells and progenitor cells in NOD/SCID mice model via inducing down-regulation of hepatic leukemia factor, SLUG, NFIL3 and c-myc, thereby inducing p53 and the mitochondrial caspase cascade, resulting in apoptosis [101].

Brassica genus contains a natural indole carbinol called glucobrassicin and hydrolytic product of glucobrassicin is indole 3 carbinol (I3C), which inhibits the proliferation of both breast cancer cell line and in vivo tumor xenograft. I3C mediates its action through targeting nucleostemin, a nucleolus residing GTPase, is a stem cell marker of breast carcinoma [102]. In proliferating cells, murine double mutant- 2 interacts with $\mathrm{p} 53$ protein through a signaling cascade. As a result, p53 cannot trigger its apoptotic response. I3C treatment promotes the interaction of nucleostemin with murine double mutant 2, an inhibitor of the p53 tumor suppressor, thereby disrupting the murine double mutant 2 interaction with $\mathrm{p} 53$. In addition, I3C induced nucleostemin to sequester murine double mutant 2 in a nucleolus compartment, thereby freeing p53 to mediate its apoptotic activity [102]. In addition, Triptolide exhibits cytotoxic effects against breast cancer stem cells by induction of apoptosis [103].
It is evident that tumor microenvironment plays a critical role in regulating breast tumor progression and signaling between preadipocytes and breast cancer cells have been found to promote breast tumor formation and metastasis [104]. It was demonstrated that Shikonin, a natural antitumor compound isolated from Lithospermum erythrorhizon, can inhibit preadipocyte signaling, and thereby inhibit nearby ductal carcinoma in situ (DCIS) cells [104]. In addition, co-culture of Shikoninwith exosome derived from preadipocyte revealed that Shikonin-treated preadipocytes secrete exosomes with high levels of miR-140, which can inhibit nearby DCIS cells by targeting SOX9 signaling [104]. SOX9, a transcription factor, promotes preadipocyte differentiation which is regulated by miR140. In cancer cells miR-140 is frequently silenced whereas treatment with Shikonin increased the expression of miR-140, resulting in the expression of SOX 9 mRNA. Thus, Shikonin alters preadipocyte differentiation by SOX/miRNA-140 pathway [104].

$\beta$-escin, a natural compound isolated from Aesculus hippocastanum, is more efficient in the killing of Glioma-Initiating Cells (GIC) by activating caspase dependent cell death when compared to that of currently used cytotoxic agents such as temozolomide, etoposide, and cisplatin [105]. Moreover, $\beta$-escin inhibits the expression of stemness markers (ALDH, SOX2, nestin) in both mesenchymal and neural glioma-initiating cells [105].

RAD51, a recombinase involved in DNA repair mechanism, and its upregulation in CSCs of cervical cancer cell line is associated with the insensitivity to etoposide [106]. Thus, targeting RAD51 still remains a promising aspect to eradicate CSCs. Resveratrol, a polyphenolic compound found abundantly in various herbs and fruits such as Arachis hypogaea, Pistacia vera, induced S phase cell cycle arrest and apoptosis of HeLa SP cells (enriched in CSCs) via downregulation of RAD51 [106]. Decreased RAD51 protein level was noted in resveratrol-treated CSCs when compared to HeLa SP without treatment or treated with etoposide alone [106]. Interesting- 
ly, the synergistic inhibitory effect of resveratrol with Etoposide was noted in HeLa SP cells [106]. In addition, resveratrol inhibits lipogenesis and cell survival of all breast cancer cell lines (MCF7, MDA-MB231, and MDA-MB231 LM) by suppressing the expression of Fatty Acid Synthase (FAS) and induces apoptosis by upregulation of pro-apoptotic genes DAPK2 and BNIP3 [107].

Koenimbin, a natural bioactive compound originated from Murraya koenigii (L) Spreng, exhibited potent growth inhibitory activity against PC-3 derived prostate CSCs and MCF7 breast CSCs $[108,109]$. It was noted that koenimbin treatment caused $G_{0} / G_{1}$ and $\mathrm{G}_{2} / \mathrm{M}$ cell cycle arrest of ALDH-positive CSCs and induced apoptosis by activating Bax and caspase expression. In addition, koenimbin caused reduced expression of Bcl-2 and HSP70 when compared to that of control cells [108, 109].

Curcumin, an active polyphenolic curcuminoid found in Curcuma longa has been traditionally used to treat many cancer types [110-112]. It has the potential to eliminate CSCs in various cancers including, breast, colon, and gliomas [110-112]. Recently, it has been reported that curcumin has an anti-CSC role against gemcitabine-resistant pancreatic CSCs [113].

Nasopharyngeal carcinoma cells (5-8F and 6-10B) expressing higher stemness markers (CD44, SOX2, c-Myc, core binding factor $\beta$, and snail) undergo apoptotic death and exhibit reduced sphere forming capacity in the presence of a naturally occurring lipophilic statin Lovastatin (found in Pleurotus ostreatus, Camellia sinensis) [114]. Moreover, lovastatin treated induced 5-8F and 6-10B cells to arrest $\mathrm{G}_{2} / \mathrm{M}$ cell cycle phase, thereby stopping cell proliferation by blocking entrance into mitosis [114]. It also sensitizes nasopharyngeal carcinoma cells CSC cells to CPA, a chemotherapeutic drug, is used to treat nasopharyngeal carcinoma cells [114].

Glioblastoma Multiforme (GBM), the most common and biologically aggressive form of a brain tumor in adults, is resistant to conventional chemo-radiotherapy [115]. The average survival rate of GBM patient is only 12-14 months after diagnosis [115]. Glioma Stem Cells (GSCs) are associated with tumor recurrence and diffuse infiltration, which aggravate the outcome of the disease [115]. Therefore, identification of compounds with the potentiality to target GSC could open new opportunity to manage this deadly disease. It was noted that Pomiferin extracted from the fruit of the Maclura pomifera, can inhibit glioma stem cell growth, invasion and sphere formation [116]. Pomiferin induced down-regulation of stemnessassociated genes i.e. BMI1, Nestin, and Nanog around 2.5-fold in GSC and thereby can be used as therapeutic agents to inhibit the growth of glioma stem cells by regulating stemness-associated genes [116].

Betulonic Acid (BA), a pentacyclic lupane-type triterpenoid, is abundantly distributed in parts of many plant species [117]. BA isolated from the bark of Walsura pinnata exhibited intrinsic apoptotic activity against Leukemia Stem Cells (LSC) [117]. In addition, it reduced the viability and colony formation of LSC in a dosedependent manner [117]. BA triggers apoptosis in LSC by increasing expression of apoptotic protein BAX while significantly reduces anti-apoptotic Bcl-2 and survivin expression [117]. Furthermore, BA increased caspase 3, caspase 7 and caspase 9 activity in LSC with the loss of mitochondrial transmembrane potential. Moreover, BA induces apoptosis in LSC xenotransplanted zebrafish through a mitochondrial pathway [117].

Induction of apoptosis is considered as an effective mechanism to eradicate CSCs and prodigiosin (2-methyl-3-pentyl-6methoxyprodigiosene) induced apoptosis of colorectal cancer stem cells (isolated from HCT-116 cells) [118]. Prodigiosin is a secondary metabolite of Serratia marcescens that can effectively reduce cell viability, proliferation via reducing survivin expression with the concomitant increment of tumor suppressor miR-16-1 expression in colorectal CSC. It also induces the activation of caspase 3, thereby promoting apoptotic death of CSCs [118].

Epigallocatechin Gallate (EGCG) reduced the viability of CD44+ and CD133+ prostate CSCs originated from PC-3 and LNCaP cell lines [119]. Furthermore, EGCG inhibited sphere forming ability of CSCs in a dose-dependent manner [119]. Interestingly, it was noted that EGCG exhibits synergistic anti-CSC activity with quercetin against prostate CSCs [119]. EGCG induces apoptosis and growth inhibition by down-regulation of Nanog, EMT, XIAP, Bcl-2 and survivin. It induces apoptosis through upregulation of caspase-3/7 [119].

BRM270 is a natural compound exhibits promising anticancer activity against many cancer types including glioblastoma, adenocarcinoma [120, 121]. For example, BRM270 induces apoptosis in MD13 glioblastoma stem cells by activating caspase-3 mediated cascade [120]. BRM270 treatment causes MD13 GSCs accumulation at $\mathrm{G}_{0}$, and then induces apoptotic cell death [120]. In addition, BRM270 inhibits stemness properties of GSCs by decreasing the expression level of CD44 and nestin [120]. It also inhibits the tumorsphere-forming capacity of MD13 GSCs [120]. Additionally, it suppresses in vivo tumor growth and cancer recurrence as well as sensitizes GSC to CCRT-a standard therapy for GBM patients [120]. Furthermore, BRM270 halts the CSC maintenance in adenocarcinoma (A549) cells by upregulation of miRNA-128 [120]. Reduced expression of miR-128 is correlated with the therapyresistant property of cancer stem cells isolated from A549 cells [120]. However, treatment with BRM270 increased the expression of miR-128 by 2-3 folds, resulting in diminishing the chemoresistant property of A549 cells [121]. Hence, different natural compound inhibits the growth of CSCs in various cancer types [120-122]. Each of them has a promising role in diminishing the proliferative effect of CSCs. It should be an outstanding perspective to design novel anticancer drugs using them in clinical trials. Moreover, it is important to investigate a new multidimentional therapeutic approach starting from cyto-reduce of the disease plus epigenetic therapy with Stem Cell Differentiation Stage Factors (SCDSFs) [123]. In addition, in case of advanced level of disease, immunotherapy can be used to treat the cancer presenting phenotype in association with chemomodulation plus ablative therapies [123]. Therefore, SCDSFs could be utilized with current cancer stem cell therapies to regulate cancer stem cells more effectively.

\section{CONCLUSION AND FUTURE PERSPECTIVES}

Advancing in the understanding of cancer initiation and maintenance by CSCs reveals that this sup-population of cells is the main culprit of cancer treatment failure because of their multiple survival mechanisms. Despite the emergence of some promising treatment options targeting normal cancer cells, lack of unique, ubiquitous and single molecular targets that affect CSCs, are becoming the major concerns of cancer therapy. In the light of this, we have attempted to make a review of natural compounds having a wide range of anti-CSCs activities. However, most of the compounds have been tested in vitro. Thus, the question remains, whether they are equally effective in vivo without adverse effects? To answer this question further research is needed. Previous findings suggest several anti-cancer drugs of natural origin and it is well established that drugs from natural origin are less toxic than their synthetic counterparts. Therefore, natural compounds with various anti-CSCs activities may have the potential to act as a source of effective chemotherapeutic solution against CSCs with no or less side effects. Interestingly, some of them exert their activity in combination with currently available chemotherapeutic agents. Thus, it opens up the opportunity that these natural compounds can be used either individually or combined with available anticancer drugs. Therefore, further research is needed to engineer robust formula- 
tions of drug or natural analogs that could effectively target CSCs without posing recognizable side effects to the patients.

\section{AVAILABILITY OF DATA AND MATERIALS:}

Not applicable

\section{CONSENT FOR PUBLICATION}

The work has not been previously published or being considered elsewhere and all the authors have contributed and agreed on the manuscript.

\section{FUNDING}

None.

\section{CONFLICT OF INTEREST}

The authors declare no conflict of interest, financial or otherwise

\section{ACKNOWLEDGEMENTS}

The University of Rajshahi, Rajshahi, Bangladesh is acknowledged for giving the technical support.

\section{REFERENCES}

[1] Khatun, M.; Habib, M.R.; Rabbi, M.A.; Amin, R.; Islam, M.F.; Nurujjaman, M.; Karim, M.R.; Rahman, M.H. Antioxidant, cytotoxic and antineoplastic effects of Carissa carandas Linn.leaves. Exp. Toxicol. Pathol., 2017, 69(7), 469-476.

[2] Reya, T.; Morrison, S.J.; Clarke, M.F., Weissman, I.L. Stem cells, cancer, and cancer stem cells. Nature, 2001, 414(6859), 105-11.

[3] Dean, M.; Fojo, T.; Bates, S. Tumour stem cells and drug resistance. Nat Rev Cancer, 2005, 5(4), 275-84.

[4] Colak, S.; Medema, J.P. Cancer stem cells--important players in tumor therapy resistance. FEBS. J., 2014, 281(21), 4779-91.

[5] White, A.C.; Lowry, W.E. Refining the role for adult stem cells as cancer cells of origin. Trends. Cell. Biol., 2015, 25(1), 11-20.

[6] O'Connor, M.L.; Xiang, D.; Shigdar, S.; Macdonald, J.; Li, Y.; Wang, T.; Pu, C.; Wang, Z.; Qiao, L.; Duan, W. Cancer stem cells: A contentious hypothesis now moving forward. Cancer. Lett., 2014, 344(2), 180-7.

[7] Geng, S.Q.; Alexandrou, A.T.; Li, J.J. Breast cancer stem cells: Multiple capacities in tumor metastasis. Cancer. Lett., 2014, 349(1), 1-7.

[8] Hermann, P.C.; Huber, S.L.; Herrler, T.; Aicher, A.; Ellwart, J.W.; Guba, M.; Bruns, C.J.; Heeschen, C. Distinct populations of cancer stem cells determine tumor growth and metastatic activity in human pancreatic cancer. Cell stem cell, 2007, 1(3), 313-23.

[9] Holohan, C.; Van Schaeybroeck, S.; Longley, D.B.; Johnston, P.G. Cancer drug resistance: an evolving paradigm. Nat. Rev. Cancer., 2013, 13(10), 714-26.

[10] Zuccarini, M.; Giuliani, P.; Ziberi, S.; Carluccio, M.; Iorio, P.D.; Caciagli, F.; Ciccarelli, R. The Role of Wnt Signal in Glioblastoma Development and Progression: A Possible New Pharmacological Target for the Therapy of This Tumor. Genes (Basel), 2018, 9(2), pii:E105.

[11] Arend, R.C.; Londoño-Joshi, A.I.; Straughn Jr, J.M.; Buchsbaum, D.J. The Wnt/ $\beta$-catenin pathway in ovarian cancer: a review. Gynecol. Oncol., 2013, 131(3), 772-9.

[12] Janovská, P.; Bryja, V. Wnt signalling pathways in chronic lymphocytic leukaemia and B-cell lymphomas. Br. J. Pharmacol., 2017, 174(24), 4701-4715.

[13] Yin, L.; Velazquez, O.C.; Liu, Z.J. Notch signaling: emerging molecular targets for cancer therapy. Biochem. Pharmacol., 2010, 80(5), 690-701.

[14] Bhardwaj, G.; Murdoch, B.; Wu, D.; Baker, D.P.; Williams, K.P.; Chadwick, K.; Ling, L.E.; Karanu, F.N.; Bhatia, M. Sonic hedgehog induces the proliferation of primitive human hematopoietic cells via BMP regulation. Nat. Immunol., 2001, 2(2), 172-80.

[15] Hu, Y.; Fu, L. Targeting cancer stem cells: a new therapy to cure cancer patients. Am J. Cancer. Res., 2012, 2(3), 340-56.
[16] Oikonomou, E.; Anastasiou, M.; Siasos, G.; Androulakis, E.; Psyrri, A.; Toutouzas, K.; Tousoulis, D. Cancer Therapeutics-Related Cardiovascular Complications. Mechanisms, Diagnosis and Treatment. Curr. Pharm. Des., 2018, 24(37), 4424-4435.

[17] Scicchitano, P.; Cameli, M.; Maiello, M.; Modesti, PA.; Muiesan, ML.; Novo, S.; Palmiero, P.; Saba, P.S.; Pedrinelli, R.; Ciccone, M.M.; di Studio Ipertensione, G. Nutraceuticals and dyslipidaemia: beyond the common therapeutics. J. Funct. Foods., 2014, 6, 11-32.

[18] Scarpa, E.S.; Ninfali, P. Phytochemicals as innovative therapeutic tools against cancer stem cells. Int. J. Mol. Sci., 2015, 16(7), 15727-42.

[19] Taylor, W.F.; Jabbarzadeh, E. The use of natural products to target cancer stem cells. Am. J. Cancer. Res., 2017, 7(7), 1588-1605.

[20] Wang, Z.; Zhang, Y.; Banerjee, S.; Li, Y.; Sarkar, F.H. Retracted: Notch-1 down-regulation by curcumin is associated with the inhibition of cell growth and the induction of apoptosis in pancreatic cancer cells. Cancer, 2006, 106(11), 2503-13.

[21] Pahlke, G.; Ngiewih, Y.; Kern, M.; Jakobs,S.; Marko, D.; Eisenbrand, G. Impact of quercetin and EGCG on key elements of the Wnt pathway in human colon carcinoma cells. J. Agric. Food. Chem., 2006, 54(19), 7075-82.

[22] Liu, S.; Dontu, G.; Wicha, M.S. Mammary stem cells, self-renewal pathways, and carcinogenesis. Breast. Cancer. Res., 2005; 7(3), 8695.

[23] Batlle, E.; Clevers, H. Cancer stem cells revisited. Nat Med, 2017, 23(10), 1124-1134.

[24] Moghbeli, M.; Moghbeli, F.; Forghanifard, M.M. Abbaszadegan MR. Cancer stem cell detection and isolation. Med. Oncol., 2014, 31(9), 69.

[25] Dontu, G.; Abdallah, W.M.; Foley, J.M.; Jackson, K.W.; Clarke, M.F.; Kawamura MJ.; Wicha, M.S. In vitro propagation and transcriptional profiling of human mammary stem/progenitor cells. Genes. Dev., 2003, 17(10), 1253-70.

[26] Islam, F.; Gopalan, V.; Smith, R.A.; Lam, A.K. Translational potential of cancer stem cells: A review of the detection of cancer stem cells and their roles in cancer recurrence and cancer treatment. Exp. Cell. Res., 2015, 335(1), 135-47.

[27] Ma, L.; Lai,D.; Liu, T.; Cheng, W.; Guo, L. Cancer stem-like cells can be isolated with drug selection in human ovarian cancer cell line SKOV3. Acta. Biochim. Biophys. Sin., 2010, 42(9), 593-602.

[28] Grosse-Gehling, P.; Fargeas, C.A.; Dittfeld, C.; Garbe, Y.; Alison, M.R.; Corbeil, D.; Kunz-Schughart, L.A. CD133 as a biomarker for putative cancer stem cells in solid tumors: limitations, problems and challenges. J. Pathol., 2013, 229(3), 355-78.

[29] Visvader, J.E.; Lindeman, G.J. Cancer stem cells in solid tumors: accumulating evidence and unresolved questions. Nat. Rev. Cancer., 2008, 8(10), 755-68.

[30] Eramo, A.; Lotti, F.; Sette, G.; Pilozzi, E.; Biffoni, M.; DiVirgilio, A.; Conticello, C.; Ruco, L.; Peschle, C.; De Maria, R. Identification and expansion of the tumorigenic lung cancer stem cell population. Cell. Death. Differ., 2008, 15(3), 504-14.

[31] Tirino, V.; Desiderio, V.; Paino,F.; Papaccio, G.; De Rosa, M. Methods for cancer stem cell detection and isolation. Methods. Mol. Biol., 2012, 879, 513-29.

[32] Ahmed, N., Escalona, R.; Leung, D.; Chan, E.; Kannourakis, G. Tumour microenvironment and metabolic plasticity in cancer and cancer stem cells: Perspectives on metabolic and immune regulatory signatures in chemoresistant ovarian cancer stem cells. Semin. Cancer. Biol., 2018, 53, 265-281.

[33] da Silva-Diz, V.; Lorenzo-Sanz, L.; Bernat-Peguera, A.; LopezCerda, M.; Muñoz, P.Cancer cell plasticity: Impact on tumor progression and therapy response. Semin. Cancer. Biol., 2018, 53, 4858.

[34] Frank, N.Y.; Schatton, T.; Frank, M.H. The therapeutic promise of the cancer stem cell concept. J. Clin. Invest., 2010, 120(1), 41-50.

[35] Islam, F.; Qiao, B.; Smith, R.A.; Gopalan, V.; Lam, A.K. Cancer stem cell: fundamental experimental pathological concepts and updates. Exp. Mol. Pathol., 2015, 98(2), 184-91.

[36] Singh, A.; Settleman, J.E.EMT, cancer stem cells and drug resistance: an emerging axis of evil in the war on cancer. Oncogene, 2010, 29(34), 4741-51.

[37] Weng, D.; Penzner, J.H.; Song, B.; Koido,S.; Calderwood, S.K.; Gong, J. Metastasis is an early event in mouse mammary carcinomas and is associated with cells bearing stem cell markers. Breast. Cancer. Res., 2012, 14, R18. 
[38] Gillies, R.J.; Schomack, P.A.; Secomb, T.W.; Raghunand, N. Causes and effects of heterogeneous perfusion in tumors. Neoplasia, 1999, 1(3), 197-207.

[39] Lee, C.H.; Wu, Y.T.; Hsieh, H.C.; Yu, Y.; Alice, L.Y.; Chang, W.W. Epidermal growth factor/heat shock protein 27 pathway regulates vasculogenic mimicry activity of breast cancer stem/progenitor cells. Biochimie, 2014,104, 117-26.

[40] Liu, C.C.; Cai, D.L.; Sun, F.; Wu, Z.H.; Yue, B.; Zhao, S.L.; Wu, X.S.; Zhang, M.; Zhu, X.W.; Peng, Z.H.; Yan, D.W. FERMT1 mediates epithelial-mesenchymal transition to promote colon cancer metastasis via modulation of $\beta$-catenin transcriptional activity. Oncogene, 2017, 36(13), 1779-92.

[41] Castilla, C.; Congregado, B.; Chinchón, D.; Torrubia, F.J.; Japón, M.A.; Sáez, C. Bcl-xL is overexpressed in hormone-resistant prostate cancer and promotes survival of $\mathrm{LNCaP}$ cells via interaction with proapoptotic Bak. Endocrinology, 2006, 147(10), 4960-7.

[42] Li, X.; Lewis, M.T.; Huang, J.; Gutierrez, C.; Osborne, C.K.; Wu, M.F.; Hilsenbeck, S.G.; Pavlick, A.; Zhang, X.; Chamness, G.C.; Wong, H. Intrinsic resistance of tumorigenic breast cancer cells to chemotherapy. J. Natl. Cancer. Inst., 2008, 100(9), 672-9.

[43] Boumahdi, S.; Driessens, G.; Lapouge, G.; Rorive, S.; Nassar, D.; Le Mercier, M.; Delatte, B.; Caauwe, A.; Lenglez, S.; Nkusi, E.; Brohée, S.; Salmon, I.; Dubois, C.; del Marmol, V.; Fuks,F.; Beck, B.; Blanpain, C. SOX2 controls tumour initiation and cancer stemcellfunctions in squamous-cell carcinoma. Nature, 2014, 511(7508), 246-50.

[44] Chiou, S.H.; Yu, C.C.; Huang, C.Y.; Lin, S.C.; Liu, C.J.; Tsai, T.H.; Chou, S.H.; Chien, C.S.; Ku, H.H.; Lo, J.F. Positive correlations of Oct-4 and Nanog in oral cancer stem-like cells and highgrade oral squamous cell carcinoma. Clin. Cancer. Res., 2008, 14(13), 4085-95.

[45] Short, S.C.; Giampieri, S.; Worku, M.; Alcaide-German, M.; Sioftanos, G.; Bourne, S.; Lio,K.I.; Shaked-Rabi, M.; Martindale C. Rad51 inhibition is an effective means of targeting DNA repair in glioma models and CD133+ tumor-derived cells. Neuro. Oncol., 2011, 13(5), 487-99.

[46] Kiyohara, E.; Tamai, K.; Katayama, I.; Kaneda, Y. The combination of chemotherapy with HVJ-E containing Rad51 siRNA elicited diverse anti-tumor effects and synergistically suppressed melanoma. Gene. Ther., 2012, 19(7), 734-41.

[47] Haraguchi, N.; Utsunomiya, T.; Inoue, H.; Tanaka, F.; Mimori, K.; Barnard, G.F.; Mori, M. Characterization of a side population of cancer cells from human gastrointestinal system. Stem cells, 2006, 24(3), 506-13.

[48] Tait, S.W.; Green, D.R. Mitochondria and cell death: outer membrane permeabilization and beyond. Nat. Rev. Mol. Cell. Biol., 2010, 11(9), 621-32.

[49] Rongxin, S.; Pengfei, L.; Li, S.; Xiaochen, J.; Yihe, H. MicroRNA340-5p suppresses osteosarcoma development by down-regulating the Wnt/ $\beta$-catenin signaling pathway via targeting the STAT3 gene. Eur. Rev. Med. Pharmacol. Sci., 2019, 23(3), 982-991.

[50] Chien, A.J.; Conrad WH, Moon RT. A Wnt survival guide: from flies to human disease. J. Invest. Dermatol., 2009, 129(7), 1614-27.

[51] Chen, Y.; Wang, X.Q.; Zhang, Q.; Zhu, J.Y.; Li, Y.; Xie, C.F.; Li, X.T.; Wu, J.S.; Geng, S.S.; Zhong, C.Y.; Han, H.Y. (-)Epigallocatechin-3-Gallate Inhibits Colorectal Cancer Stem Cells by Suppressing Wnt/ $\beta$-Catenin Pathway. Nutrients, 2017, 9(6), 572, piiE572

[52] Zhang, Q.; Li, X.T.; Chen, Y.; Chen, J.Q.; Zhu, J.Y.; Meng, Y.; Wang, X.Q.; Li, Y.; Geng, S.S.; Xie, C.F.; Wu, J.S. Wnt/ $\beta$-catenin signaling mediates the suppressive effects of diallyl trisulfide on colorectal cancer stem cells. Cancer. Chemother. Pharmacol., 2018, 81(6), 969-77.

[53] Zhang, Y.; Chen, S.; Wei, C.;Rankin, G.O.; Ye, X.; Chen, Y.C. Dietary compound proanthocyanidins from Chinese bayberry (Myrica rubra Sieb. et Zucc.) leaves attenuate chemotherapy-resistant ovarian cancer stem cell traits via targeting the Wnt/ $\beta$-catenin signaling pathway and inducing G1 cell cycle arrest. Food. Funct., 2018, 9(1), 525-33.

[54] Deng, S.; Wong, C.K.; Lai, H.C.; Wong, A.S. Ginsenoside-Rb1 targets chemotherapy-resistant ovarian cancer stem cells via simultaneous inhibition of $\mathrm{Wnt} / \beta$-catenin signaling and epithelial-tomesenchymal transition. Oncotarget, 2017, 8(16), 25897-914.

[55] Li, Y.; Zhang, T.; Korkaya, H.; Liu, S.; Lee, H.F.; Newman, B.; Yu, Y.; Clouthier, S.G.; Schwartz, S.J.; Wicha, M.S.; Sun, D. Sulforaphane, a dietary component of broccoli/broccoli sprouts, inhib- its breast cancer stem cells. Clin. Cancer. Res., 2010, 16(9), 258090 .

[56] Wang, N.; Wang, Z.; Wang, Y.; Xie, X.; Shen, J.; Peng, C.; You, J.; Peng, F.; Tang, H.; Guan, X.; Chen, J. Dietary compound isoliquiritigenin prevents mammary carcinogenesis by inhibiting breast cancer stem cells through WIF1 demethylation. Oncotarget, 2015, 6(12), 9854-76.

[57] Wang, N.; Wang, Z.; Peng, C.; You, J.; Shen, J.; Han, S.; Chen, J. Dietary compound isoliquiritigenin targets GRP78 to chemosensitize breast cancer stem cells via $\beta$-catenin/ABCG2 signaling. Carcinogenesis, 2014, 35(11), 2544-54.

[58] Luo, K.; Chen, W.; Lung, W.; Wei, X.; Cheng, B.; Cai, Z.; Huang, W. EGCG inhibited bladder cancer SW780cell proliferation and migration both in vitro and in vivo via down-regulation of NFkappa B and MMP-9. J. Nutr. Biochem., 2017, 41, 56-64.

[59] Zhang, J.; Lei, Z.; Huang, Z.; Zhang, X.; Zhou, Y.; Luo, Z.;Zeng, W.; Su, J.; Peng, C.; Chen, X. Epigallocatechin-3-gallate(EGCG) suppresses melanoma cell growth and metastasis by targeting TRAF6activity. Oncotarget, 2016, 7(48), 79543-79557.

[60] Li, M.; Li, J.J.; Gu, Q.H.; An, J.; Cao, L.M.; Yang, H.P.; Hu, C.P. EGCG induces lung cancerA549 cell apoptosis by regulating $\mathrm{Ku} 70$ acetylation. Oncol. Rep., 2016, 35(4), 2339-47.

[61] Lee, J.C.; Chung, L.C.; Chen, Y.J.; Feng, T.H.; Chen, W.T.; Juang, H.H.; Upregulation of B-cell translocation gene 2 by epigallocatechin-3-gallate via p38 and ERK signaling blocks cell proliferation in human oral squamous cell carcinoma cells. Cancer. Lett., 2015, 360(2), 310-318.

[62] Cerezo-Guisado, M.I.; Zur, R.; Lorenzo, M.J.; Risco, A.; MartinSerrano, M.A.; Alvarez-Barrientos, A.; Cuenda, A.; Centeno, F. Implication of Akt, ERK1/2 and alternative p38MAPK signalling pathways inhuman colon cancer cell apoptosis induced by green tea EGCG. Food. Chem. Toxicol., 2015, 84, 125-132.

[63] Liang, J.; Hänsch, G.M.; Hübner, K.; Samstag, Y. Sulforaphane as anticancer agent: A double-edged sword? Tricky balance between effects on tumor cells and immune cells. Adv. Biol. Regul., 2019, 71, 79-87.

[64] Koch, U.; Lehal, R.; Radtke, F. Stem cells living with a Notch. Development, 2013, 140(4), 689-704.

[65] Androutsellis-Theotokis, A.; Leker, R.R.; Soldner, F.; Hoeppner, D.J.; Ravin, R.; Poser, S.W.; Rueger, M.A.; Bae, S.K.; Kittappa, R.; McKay, R.D. Notch signalling regulates stem cellnumbers in vitro and in vivo. Nature, 2006, 442(7104), 823-6.

[66] Espinoza, I.; Pochampally, R.; Xing, F.; Watabe, K.; Miele, L. Notch signaling: targeting cancer stem cells and epithelial-tomesenchymal transition. Onco.Targets. Ther., 2013, 6, 1249-59.

[67] Wang, J.; Yan, Z.; Liu, X.; Che, S.; Wang, C.; Yao, W. Alpinetin targets glioma stem cells by suppressing Notch pathway. Tumor. Biol., 2016, 37(7), 9243-8.

[68] Hyun, K.H.; Yoon, C.H.; Kim, R.K.; Lim, E.J.; An, S.; Park, M.J.; Hyun, J.W.; Suh, Y.; Kim, M.J.; Lee, S.J. Eckol suppresses maintenance of stemness and malignancies in glioma stem-like cells. Toxicol. Appl. Pharmacol., 2011, 254(1), 32-40.

[69] Kallifatidis, G.; Labsch, S.; Rausch, V.; Mattern, J.; Gladkich, J.; Moldenhauer, G.; Büchler, M.W.; Salnikov, A.V.; Herr, I. Sulforaphane increases drug-mediated cytotoxicity toward cancer stem-like cells of pancreas and prostate. Mol. Ther., 2011, 19(1), 188-95.

[70] Kaushik, G.; Venugopal, A.; Ramamoorthy, P.; Standing, D.; Subramaniam, D.; Umar, S.; Jensen, R.A.; Anant, S.; Mammen, J.M. Honokiol inhibits melanoma stem cells by targeting notch signaling. Mol. Carcinog., 2015, 54(12), 1710-21.

[71] McMahon, A.P.; Ingham, P.W.; Tabin, C.J. Developmental roles and clinical significance of hedgehog signaling. Curr. Top. Dev. Biol., 2003, 53, 1-114.

[72] Varjosalo, M.; Taipale, J. Hedgehog: functions and mechanisms. Genes. Dev., 2008, 22(18), 2454-72.

[73] Kobune, M.; Takimoto, R.; Murase, K.; Iyama, S.; Sato, T.; Kikuchi, S.; Kawano, Y.; Miyanishi, K.; Sato, Y.; Niitsu, Y.; Kato, J. Drug resistance is dramatically restored by hedgehog inhibitors in CD34+ leukemic cells. Cancer. Sci.; 2009, 100(5), 948-55.

[74] Sun, M.; Zhang, N.; Wang, X.; Li, Y.; Qi,W.; Zhang, H.; Li, Z.; Yang, Q. Hedgehog pathway is involved in nitidine chloride induced inhibition of epithelial-mesenchymal transition and cancer stem cells-like properties in breast cancer cells. Cell. Biosci., 2016, 6,44 . 
[75] Rodova, M.; Fu, J.; Watkins, D.N.; Srivastava, R.K.; Shankar, S. Sonic hedgehog signaling inhibition provides opportunities for targeted therapy by sulforaphane in regulating pancreatic cancer stem cell self-renewal. PloS One, 2012, 7(9), e46083.

[76] Fan, P.; Fan, S.; Wang, H.; Mao, J.; Shi, Y.; Ibrahim, M.M.; Ma, W.; Yu, X.; Hou, Z.; Wang B.; Li, L. Genistein decreases the breast cancer stem-like cell population through Hedgehog pathway. Stem. Cell. Res. Ther., 2013, 4(6), 146.

[77] Zhu, J.; Wang, H.; Sun, Q.; Ji, X.; Zhu, L.; Cong, Z.; Zhou, Y.; Liu, H.; Zhou, M. Nrf2 is required to maintain the self-renewal of glioma stem cells. BMC Cancer, 2013, 13, 380.

[78] Yang, F.; Nam, S.; Zhao, R.; Tian, Y.; Liu, L.; Horne, D.A.; Jove, R. A novel synthetic derivative of the natural product berbamine inhibits cell viability and inducesapoptosis of human osteosarcoma cells, associated with activation of JNK/AP-1 signaling. Cancer. Biol. Ther., 2013, 14(11), 1024-31.

[79] Mongre, R.K.; Sodhi, S.S.; Ghosh, M.; Kim, J.H.; Kim, N.; Park, Y.H.; Kim, S.J.; Heo, Y.J.; Sharma, N.; Jeong, D.K. The novel inhibitor BRM270 downregulates tumorigenesis by suppression of $\mathrm{NF}-\kappa \mathrm{B}$ signaling cascade in MDR-induced stem like cancerinitiating cells. Int. J. Oncol., 2015, 46(6), 2573-85.

[80] Lau, A.; Villeneuve, N.F.;Sun, Z.; Wong, P.K.; Zhang, D.D. Dual roles of Nrf2 in cancer. Pharmacol. Res., 2008, 58(5-6), 262-70.

[81] Fabrizio, F.P.; Costantini, M.; Copetti, M.; la Torre, A.; Sparaneo, A.; Fontana, A.; Poeta, L.; Gallucci, M.; Sentinelli, S.; Graziano, P.; Parente, P.; Pompeo, V.; De Salvo, L.; Simone, G.; Papalia, R.; Picardo, F.; Balsamo, T.; Flammia, G.P.; Trombetta, D.; Pantalone, A.; Kok, K.; Paranita, F.; Muscarella, L.A.; Fazio, V.M. Keap1/Nrf2 pathway in kidney cancer: frequent methylation of KEAP1 gene promoter in clear renal cell carcinoma. Oncotarget, 2017, 8(7), 11187-11198.

[82] Almeida, M.; Soares, M.; Ramalhinho, A.C.; Moutinho, J.F.; Breitenfeld, L. Prognosis of hormone-dependent breast cancer seems to be influenced by KEAP1, NRF2 and GSTM1 genetic polymorphisms. Mol. Biol. Rep., 2019, 1-12.

[83] Zhang, H.S.; Zhang, Z.G.; Du, G.Y.; Sun, HL.; Liu, H.Y.; Zhou, Z.; Gou, X.M.; Wu, X.H.; Yu, X.Y.; Huang, Y.H. Nrf2 promotes breast cancer cell migration via up-regulation of G6PD/HIF$1 \alpha /$ Notch1 axis. J. Cell. Mol. Med., 2019, 23(5), 3451-3463.

[84] Zhang, B.; Ma, Z.; Tan, B.; Lin, N. Targeting the cell signaling pathway Keap1-Nrf2 as a therapeutic strategy for adenocarcinomas of the lung. Expert. Opin. Ther. Targets., 2019, 23(3), 241-250.

[85] Pan, S.T, Qin, Y.; Zhou, Z.W.; He, Z.X.; Zhang, X.; Yang, T.; Yang, Y.X.; Wang, D.; Zhou, S.F.; Qiu, J.X. Plumbagin suppresses epithelial to mesenchymal transition and stemness via inhibiting Nrf2-mediated signaling pathway in human tongue squamous cell carcinoma cells. Drug. Des. Devl. Ther., 2015, 9, 5511-51.

[86] Siveen, K.S.; Uddin, S.; Mohammad, R.M. Targeting acute myeloid leukemia stem cell signaling by natural products. Mol. Cancer., 2017, 16(1), 13.

[87] Yang, F.; Nam, S.; Brown, C.E.; Zhao, R.; Starr, R.; Horne, D.A.; Malkas, L.H.; Jove, R.; Hickey, R.J. A novel berbamine derivative inhibits cell viability and induces apoptosis in cancer stem-like cells of human glioblastoma, via up-regulation of miRNA-4284 and JNK/AP-1 signaling. PloS One, 2014, 9(4), e94443.

[88] Yang, F.; Nam, S.; Zhao, R.; Tian, Y.; Liu, L.; Horne, D.A.; Jove, R. A novel synthetic derivative of the natural product berbamine inhibits cell viability and induces apoptosis of human osteosarcoma cells, associated with activation of JNK/AP-1 signaling. Cancer. Biol. Ther., 2013, 14(11), 1024-31.

[89] Deng, R.; Wang, X.; Liu, Y.; Yan, M.; Hanada, S.; Xu, Q.; Zhang, J.; Han, Z.; Chen, W.; Zhang, P. A new gamboge derivative Compound 2 inhibits cancer stem-like cells via suppressing EGFR tyrosine phosphorylation in head and neck squamous cell carcinoma. J. Cell. Mol. Med., 2013, 17(11), 1422-33.

[90] Yu, S.L.; Chen, H.Y.; Chang, G.C.; Chen, C.Y.; Chen, H.W.; Singh, S.; Cheng, C.L.; Yu, C.J.; Lee, Y.C.; Chen, H.S.; Su, T.J. MicroRNA signature predicts survival and relapse in lung cancer. Cancer cell, 2008, 13(1), 48-57.

[91] Seike, M.; Goto, A.; Okano, T.; Bowman, E.D.; Schetter, A.J.; Horikawa, I.; Mathe, E.A.; Jen, J.; Yang, P.; Sugimura, H.; Gemma, A. MiR-21 is an EGFR-regulated anti-apoptotic factor in lung cancer in never-smokers. Proc. Natl. Acad. Sci. U S A., 2009, 106(29), 12085-90.

[92] Iorio, M.V.; Casalini, P.; Tagliabue, E.; Menard, S.; Croce, C.M. MicroRNA profiling as a tool to understand prognosis, therapy re- sponse and resistance in breast cancer. Eur. J. Cancer., 2008, 44(18), 2753-9.

[93] Zhu, K.; Ding, H.; Wang, W.; Liao, Z.; Fu, Z.; Hong, Y.; Zhou, Y.; Zhang, C.Y.; Chen, X. Tumor-suppressive miR-218-5p inhibits cancer cell proliferation and migration via EGFR in non-small cell lung cancer. Oncotarget, 2016, 7(19), 28075-85.

[94] Zhang, S.; Hong, Z.; Li, Q.; Lei, J.; Huang, H.; Liu, Q. Effect of MicroRNA-218 on the viability, apoptosis and invasion of renal cell carcinoma cells under hypoxia by targeted downregulation of CXCR7 expression. Biomed. Pharmacother., 2016, 80, 213-9.

[95] Kumamoto, T.; Seki,N.; Mataki, H.; Mizuno, K.; Kamikawaji, K. Samukawa, T.; Koshizuka, K.; Goto, Y.; Inoue, H. Regulation of TPD52 by antitumor microRNA-218 suppresses cancer cell migration and invasion in lung squamous cell carcinoma. Int. J. Oncol., 2016, 49(5), 1870-80.

[96] Yang, P.Y.; Hsieh, P.L.; Wang, T.H.; Yu, C.C.; Lu, M.Y.; Liao, Y.W.; Lee, T.H.; Peng, C.Y. Andrographolide impedes cancer stemness and enhances radio-sensitivity in oral carcinomas via miR-218 activation. Oncotarget, 2017, 8(3), 4196.

[97] Tu, D.G.; Yu, Y.; Lee, C.H.; Kuo, Y.L.; Lu, Y.C.; Tu, C.W Chang, W.W. Hinokitiol inhibits vasculogenic mimicry activity of breast cancer stem/progenitor cells through proteasome-mediated degradation of epidermal growth factor receptor. Oncol. Lett., 2016, 11(4), 2934-40.

[98] Ouyang, W.C.; Liao, Y.W.; Chen, P.N.; Lu, K.H.; Yu, C.C.; Hsieh, P.L. Hinokitiol suppresses cancer stemness and oncogenicity in glioma stem cells by Nrf2 regulation. Cancer. Chemother. Pharmacol., 2017, 80(2), 411-9.

[99] Hu, F.W.; Yu, C.C.; Hsieh, P.L.; Liao, Y.W.; Lu, M.Y.; Chu, P.M. Targeting oral cancer stemness and chemoresistance by isoliquiritigenin-mediated GRP78 regulation. Oncotarget, 2017, 8(55), 93912.

[100] Yin, Y.; Chen, C.; Chen, J.; Zhan, R.;Zhang, Q.; Xu, X.; Li, D.; Li, M. Cell surface GRP78 facilitates hepatoma cells proliferation and migration by activating IGF-IR. Cell Signal, 2017, 35, 154-62.

[101] Kwon, T.; Zhang, J.J.; Sharma, N.; Gera, M.; Ghosh, M.; Kim, N.; Cho, S.K.; Lee, D.S.; Park, Y.H.; Jeong, D.K. Wogonin suppresses stem cell-like traits of CD133 positive osteosarcoma cell via inhibiting matrix metallopeptidase-9 expression. BMC. Complement. Altern. Med., 2017, 17(1), 304.

[102] Dorn, D.C.;Kou, C.A.; Png, K.J.; Moore, M.A. The effect of cantharidins on leukemic stem cells. Int. J. Cancer., 2009, 124(9), 2186-99

[103] Tin, A.S.; Park, A.H.; Sundar, S.N.; Firestone, G.L. Essential role of the cancer stem/progenitor cell marker nucleostemin for indole3-carbinol anti-proliferative responsiveness in human breast cancer cells. BMC. Biol., 2014, 12(1), 72.

[104] Li, J.; Liu, R.; Yang, Y.; Huang, Y.; Li, X.; Liu, R.; Shen, X. Triptolide-induced in vitro and in vivo cytotoxicity in human breast cancer stem cells and primary breast cancer cells. Oncol. Rep. 2014, 31(5), 2181-6.

[105] Gernapudi, R.; Yao, Y.; Zhang, Y.; Wolfson, B.; Roy, S.; Duru, N.; Eades, G.; Yang, P.; Zhou, Q. Targeting exosomes from preadipocytes inhibits preadipocyte to cancer stem cell signaling in earlystage breast cancer. Breast. Cancer. Res. Treat., 2015, 150(3), 68595.

[106] Harford-Wright, E.; Bidère, N.; Gavard, J. $\beta$-escin selectively targets the glioblastoma-initiating cell population and reduces cell viability. Oncotarget, 2016, 7(41), 66865.

[107] Ruíz, G.; Valencia-González, H.A.; León-Galicia, I.; García-Villa, E.; García-Carrancá, A.; Gariglio, P. Inhibition of RAD51 by siRNA and Resveratrol Sensitizes Cancer Stem Cells Derived from HeLa Cell Cultures to Apoptosis. Stem. Cells. Int., 2018, 2018, 2493869.

[108] Pandey, P.R.; Okuda, H.; Watabe, M.; Pai, S.K.; Liu, W.; Kobayashi, A.; Xing, F.; Fukuda, K.; Hirota, S.; Sugai, T.; Wakabayashi, G. Resveratrol suppresses growth of cancer stem-like cells by inhibiting fatty acid synthase. Breast. Cancer. Res. Treat., 2011, 130(2), 387-98.

[109] Kamalidehghan, B.; Ghafouri-Fard, S.; Motevaseli, E.; Ahmadipour, F. Inhibition of human prostate cancer (PC-3) cells and targeting of PC-3-derived prostate cancer stem cells with koenimbin, a natural dietary compound from Murraya koenigii (L) Spreng. Drug. Des. Devel. Ther., 2018, 12, 1119.

[110] Ahmadipour, F.; Noordin, M.I.; Mohan, S.; Arya, A.; Paydar, M.; Looi, C.Y.; Keong Y.S.; Siyamak, E.N.; Fani, S.; Firoozi, M.; Yong, C.L.; Sukari, M.A.; Kamalidehghan, B. Koenimbin, a natu- 
ral dietary compound of Murraya koenigii (L) Spreng: inhibition of MCF7 breast cancer cells and targeting of derived MCF7 breast cancer stem cells (CD44(+)/CD24(-/low)): an in vitro study. Drug. Des. Devel. Ther., 2015, 9, 1193-208.

[111] Fong, D.; Yeh, A.; Naftalovich, R.; Choi, TH.; Chan, M.M. Curcumin inhibits the side population (SP) phenotype of the rat C6 glioma cell line: towards targeting of cancer stem cells with phytochemicals. Cancer. Lett., 2010, 293(1), 65-72.

[112] Yu, Y.; Kanwar, S.S.; Patel, B.B.; Nautiyal, J.; Sarkar, F.H.; Majumdar, A.P. Elimination of colon cancer stem-like cells by the combination of curcumin and FOLFOX. Transl. Oncol., 2009, 2(4), 321-8.

[113] Kakarala, M.; Brenner, D.E.; Korkaya, H.; Cheng, C.; Tazi, K.; Ginestier, C.;Liu, S.; Dontu, G.; Wicha, M.S. Targeting breast stem cells with the cancer preventive compounds curcumin and piperine. Breast. Cancer. Res. Treat., 2010, 122(3), 777-85.

[114] Bao, B.; Ali, S.; Kong, D.; Sarkar, S.H.; Wang, Z.; Banerjee, S.; Aboukameel, A.; Padhye, S.; Philip, P.A.; Sarkar, F.H. Anti-tumor activity of a novel compound-CDF is mediated by regulating miR21, miR-200, and PTEN in pancreatic cancer. PloS One, 2011, 6(3), e17850.

[115] Peng, Y.; He, G.; Tang, D.; Xiong, L.; Wen, Y.; Miao, X.; Hong, Z.; Yao, H.; Chen, C.; Yan, S.; Lu, L.; Yang, Y.; Li, Q.; Deng, X. Lovastatin Inhibits Cancer Stem Cells and Sensitizes to Chemo-and Photodynamic Therapy in Nasopharyngeal Carcinoma. J. Cancer., 2017, 8(9), 1655.

[116] Hothi, P.; Martins, T.J.; Chen, L.; Deleyrolle, L.; Yoon,J.G.; Reynolds, B.; Foltz, G. High-throughput chemical screens identify disulfiram as an inhibitor of human glioblastoma stem cells. Oncotarget, 2012, 3(10), 1124

[117] Zhao, D.; Yao, C.; Chen, X.; Xia, H.; Zhang, L.; Liu,H.; Jiang, X.; Dai, Y.; Liu, J. The fruits of Maclura pomifera extracts inhibits glioma stem-like cell growth and invasion. Neurochem. Res., 2013, 38(10), 2105-13.
[118] Leong, K.H.; Mahdzir, M.A.; Din, M.F.; Awang, K.; Tanaka, Y.; Kulkeaw, K.; Ishitani, T.; Sugiyama, D. Induction of intrinsic apoptosis in leukaemia stem cells and in vivo zebrafish model by betulonic acid isolated from Walsura pinnata Hassk (Meliaceae) Phytomedicine, 2017, 26, 11-21.

[119] Sam, S.; Sam, M.R.; Esmaeillou, M.; Safaralizadeh, R. Effective targeting survivin, caspase-3 and microRNA-16-1 expression by methyl-3-pentyl-6-methoxyprodigiosene triggers apoptosis in colorectal cancer stem-like cells. Pathol. Oncol. Res., 2016, 22(4), 71523.

[120] Tang, S.N.; Singh, C.; Nall, D.; Meeker, D.;Shankar, S.; Srivastava, R.K. The dietary bioflavonoid quercetin synergizes with epigallocathechin gallate (EGCG) to inhibit prostate cancer stem cell characteristics, invasion, migration and epithelial-mesenchymal transition. J. Mol. Signal., 2010, 5(1), 14.

[121] Jeon, H.Y.; Park, C.G.; Ham, S.W.; Choi, S.H.; Lee, SY.; Kim, J.Y.; Seo,S.; Jin, X.; Kim, J.K.; Eun, K.; Kim, E.J. BRM270, a Compound from Natural Plant Extracts, Inhibits Glioblastoma Stem Cell Properties and Glioblastoma Recurrence. J. Med. Food., 2017, 20(9), 838-45.

[122] Kwon, T.; Chandimali,N.; Zhang, J.J.; Kim, N.; Bak, Y.; Yoon, D.Y.; Yu, D.Y.; Lee, J.C.; Gera, M.; Ghosh, M.; Park, Y.H. BRM270 inhibits cancer stem cell maintenance via microRNA regulation in chemoresistant A549 lung adenocarcinoma cells. Cell. Death. Dis., 2018, 9(2), 244.

[123] Lugnani, F.; Simone, G.; Biava, P.M.; Ablin, R.J. The role of neuroendocrine cells in prostate cancer: a comprehensive review of current literature and subsequent rationale to broaden and integrate current treatment modalities. Curr. Med. Chem., 2014, 21(9), 1082-92.

[124] Kong, W.; Wei, J.; Abidi, P.; Lin, M.; Inaba, S.; Li, C.; Wang, Y.; Wang, Z.; Si, S.; Pan, H.; Wang, S.; Wu, J.; Wang, Y.; Li, Z.; Liu, J.; Jiang, J.D. Berberine is a novel cholesterol-lowering drug working through a unique mechanism distinct from statins. Nat. Med., 2004, 10(12), 1344-51. 